\title{
Simultaneously assimilating multivariate data sets into the two-source evapotranspiration model by Bayesian approach: application to spring maize in an arid region of northwestern China
}

\author{
G. F. Zhu ${ }^{1}$, X. $\mathrm{Li}^{2}$, Y. H. Su${ }^{2}$, K. Zhang ${ }^{1}$, Y. Bai ${ }^{1}$, J. Z. $\mathrm{Ma}^{1}$, C. B. $\mathrm{Li}^{1}$, X. L. Hu ${ }^{2}$, and J. H. He \\ ${ }^{1}$ Key Laboratory of Western China's Environmental Systems (Ministry of Education), Lanzhou University, \\ Lanzhou 730000, China \\ ${ }^{2}$ Cold and Arid Regions Environmental and Engineering Research Institute, Chinese Academy of Science, \\ Lanzhou 730000, China
}

Correspondence to: G. F. Zhu (zhugf@1zu.edu.cn)

Received: 12 December 2013 - Published in Geosci. Model Dev. Discuss.: 21 January 2014

Revised: 13 April 2014 - Accepted: 10 June 2014 - Published: 17 July 2014

\begin{abstract}
Based on direct measurements of half-hourly canopy evapotranspiration (ET; $\mathrm{W} \mathrm{m}^{-2}$ ) using the eddy covariance (EC) system and daily soil evaporation ( $E$; $\mathrm{mm} \mathrm{day}^{-1}$ ) using microlysimeters over a crop ecosystem in arid northwestern China from 27 May to 14 September in 2013, a Bayesian method was used to simultaneously parameterize the soil surface and canopy resistances in the Shuttleworth-Wallace (S-W) model. Four of the six parameters showed relatively larger uncertainty reductions $(>50 \%)$, and their posterior distributions became approximately symmetric with distinctive modes. There was a moderately good agreement between measured and simulated values of halfhourly ET and daily $E$ with a linear regression being $y=$ $0.84 x+0.18\left(R^{2}=0.83\right)$ and $y=1.01 x+0.01\left(R^{2}=0.82\right)$, respectively. The causes of underestimations of ET by the SW model was possibly attributed to the microscale advection, which can contribute an added energy in the form of downward sensible heat fluxes to the ET process. Therefore, the advection process should be taken into account in simulating ET in heterogeneous land surfaces. Also, underestimations were observed on or shortly after rainy days, which may be due to direct evaporation of liquid water intercepted in the canopy. Thus, the canopy interception model should be coupled to the S-W model in the long-term ET simulation.
\end{abstract}

\section{Introduction}

In agriculture ecosystems, more than $90 \%$ of all water inputs is lost by evapotranspiration (ET) (Morison et al., 2008), which is defined as the sum of water loss by evaporation $(E)$ from soil and transpiration $(T)$ from plants (Rana and Katerji, 2000). $E$ and $T$ are influenced by different abiotic and biotic factors (Wang and Yakir, 2000), and the contributions of $E$ and $T$ to the total ecosystem ET are highly variable in space and time (Ferretti et al., 2003). Thus, accurate measurement or estimation of ET and its components $(E$ and $T$ ) is essential for many applications in agriculture, such as irrigation scheduling, drainage, and yield forecasts (Wallace and Verhoef, 2000; Flumignan et al., 2011; Sun et al., 2012). The Shuttleworth-Wallace model (S-W model) (Shuttleworth and Wallace, 1985) takes the interactions between the fluxes from soil and canopy into account, and is physically sound and rigorous. Previous studies have proved that it performs well for row crops such as maize, wheat, cotton, sorghum and vine (Stannard, 1993; Tourula and Heikinheimo, 1998; Anadranistakis et al., 2000; Teh et al., 2001; Lund and Soegaard, 2003; Kato et al., 2004; Ortega-Farias et al., 2007; Zhang et al., 2008).

Despite these studies, there are still some insufficiencies in the application of the S-W model (Hu et al., 2009; Zhu et al., 2013). First, the S-W model is sensitive to the errors in the values of canopy and soil resistances (Lund and Soegaard, 2003). Previous studies mainly focused on the parameterization of the canopy resistance (Hanan and Prince, 
1997; Samanta et al., 2007; Zhu et al., 2013), and less attentions have been committed to the parameterization of the soil surface resistance (Sellers et al., 1992; van de Griend and Owe, 1994; Villagarcía et al., 2010). In crop ecosystem, $E$ may contribute significantly to the total ET when leaf area index (LAI) is low (Lund and Soegaard, 2003; Zhang et al., 2008). Thus, simultaneous parameterization of the canopy and soil resistances in the S-W model, based on direct measurement of ET and its components by using a combination of micrometeorological (e.g., eddy covariance methods, Bowen ratio), hydrological (e.g., chambers, microlysimeters) and ecophysiological techniques (e.g., sap flow, stable isotopes) (Williams et al., 2004; Scott et al., 2006), is important to reduce the model error. However, such studies are relatively rare or nonexistent. Secondly, as far as the parameterization method is concerned, abundant evidence has shown that the Bayesian method provides a powerful new tool to simultaneously optimize many or all model parameters against all available measurements, and to quantify the influence of uncertainties (Clark and Gelfand, 2006). Although some pioneering efforts have been made (e.g., Samanta et al., 2007; Zhu et al., 2013), the Bayesian method has been much less frequently used in parameterization of ET models than in the other environmental sciences (van Oijen et al., 2005). Moreover, the Bayesian method, to our knowledge, has not been used to simultaneously optimize the parameters of the S-W model against multivariate data sets (Sect. 2.5). Finally, arid northwestern China, one of the driest areas in the world (Zhu et al., 2007, 2008), is characterized by a widely distributed Gobi desert interspersed with many oases in different sizes and shapes. Land surface processes of this heterogeneous region are much more complex than in other regions (Zhang and Huang, 2004). Thus, the applicability of the S-W model in such regions needs to be investigated in detail.

Based on direct measurements of different components of ET obtained by using the eddy covariance technique and microlysimeters over a spring maize field in the arid region of northwestern China from 27 May to 14 September in 2012, the objectives of the present study were to (1) simultaneously parameterize the S-W model using the Bayesian method against multivariate data sets, and (2) verify the performances of the S-W model, and identify the causes of failure and success in simulating ET over the crop ecosystem in arid desert oases of northwestern China. It is expected that this study can not only promote the development of ET model parameterization, but also help us to find a proper direction in modifying the $\mathrm{S}-\mathrm{W}$ model used in arid regions.

\section{Materials and methods}

\subsection{Study site}

The study site is located in the Daman (DM) Oasis, in the middle Heihe River basin, Gansu Province, China $\left(100^{\circ} 22^{\prime} 20^{\prime \prime}\right.$ E, $38^{\circ} 51^{\prime} 20^{\prime \prime} \mathrm{N}$; $1556 \mathrm{~m}$ a.s.l.; Fig. 1$)$. The annual average temperature and precipitation was $7.2^{\circ} \mathrm{C}$ and $125 \mathrm{~mm}$ (1960-2000), respectively. The potential evaporation is around $2365 \mathrm{~mm}_{\text {year }}{ }^{-1}$, and the dryness index according to the World Atlas of Desertification (UNEP, 1992) is 15.9. The soil type is silt clay loam on the surface and silt loam in the deeper layer.

The study area has an agricultural development history of over 2000 years owing to its flat terrain, adequate sunlight and convenient water resources from the Qilian Mountains. The main crops in the DM Oasis are spring wheat and maize. The spring wheat (Triticum aestivum L.) is generally sown in late March and harvested in the middle 10 days of July, while the maize (Zea mays L.) is sown in late April and harvested in the middle 10 days of September. Stand density of the spring maize is about 37 plants $\mathrm{m}^{2}$ with row spacing of $40 \mathrm{~cm}$ and planting spacing of $7 \mathrm{~cm}$.

\subsection{Measurements and data processing}

The field observation systems at this site were constructed in May 2012 as part of the Heihe Watershed Allied Telemetry Experimental Research (HiWATER) project (see details in $\mathrm{Li}$ et al., 2013b). The fluxes of sensible heat $(H)$, latent heat $(\lambda \mathrm{ET})$ and carbon dioxide were measured at the height of $4.5 \mathrm{~m}$ using the eddy covariance (EC) system (Liu et al., 2014, manuscript in preparation), which consists of an open-path infrared gas analyzer (Li-7500, LiCor Inc., Lincoln, NE, USA) and a 3-D sonic anemometer (CSAT-3, Campbell Scientific Inc., Logan, UT, USA). The EC data were sampled at a frequency of $10 \mathrm{~Hz}$ by a data logger (CR5000, Campbell Scientific Inc.), and then were processed with an average time of $30 \mathrm{~min}$. Post-processing calculations, using EdiRe software, included spike detection, lag correction of $\mathrm{H}_{2} \mathrm{O} / \mathrm{CO}_{2}$ relative to the vertical wind component, sonic virtual temperature conversion, planar fit coordinate rotation, the WPL (Webb-Pearman-Leuning) density fluctuation correction and frequency response correction (Xu et al., 2014). About $85 \%$ of the energy balance closure (the sum of $H+\lambda \mathrm{ET}$ against the available energy) was found in EC data (Liu et al., 2011). In addition, the flux uncertainties are directly related to the likelihood function of Bayesian inference (Sect. 2.5). Thus, determining the uncertainties in EC measurements is essential for proper parameter estimates. Recently, Wang et al. (2014) systemically studied the flux uncertainties of EC systems equipped in the HiWATER experiment. Generally, uncertainties for $H\left(\sigma_{r}(H)\right.$; $\mathrm{W} \mathrm{m}^{-2}$ ) by using the method of Mann and Lenschow (1994) tended to be $\sigma_{r}(H)=0.14 H+2.7\left(R^{2}=0.95\right)$, and uncertainties for $\lambda \mathrm{ET}\left(\sigma_{r}(\lambda \mathrm{ET}) ; \mathrm{W} \mathrm{m}^{-2}\right)$ tended to be $\sigma_{r}(\lambda \mathrm{ET})=$ $0.13 \lambda \mathrm{ET}+6\left(R^{2}=0.93\right)$ (Wang et al., 2014). Data gaps due to instrument malfunction, power failure and bad weather conditions were filled using artificial neural network (ANN) and mean diurnal variations (MDV) methods (Falge et al., 2001). The ANN method was applied when the synchronous 


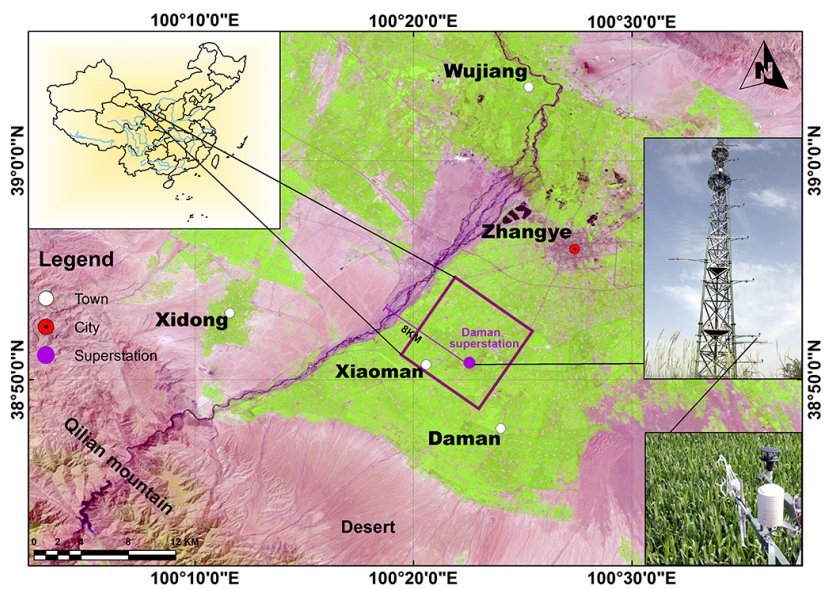

Figure 1. Experimental location and instrumentation setting at the Daman (DM) superstation.

meteorological data were available; otherwise, the MDV method was used. The gap-filling data were used only to analyze the seasonal and annual variations in ET.

Continuous complementary measurements also included standard hydro-meteorological variables. Rainfall was measuring using a tipping bucket rain gauge (TE525MM, Campbell Scientific Instruments Inc.). Air temperature, relative humidity (HMP45C, Vaisala Inc., Helsinki, Finland) and wind speed/direction (034B, Met One Instruments Inc., USA) were measured at heights of 3, 5, 10 15, 20,30 and $40 \mathrm{~m}$ above the ground. Downward and upward solar and longwave radiation (PSP, The EPPLEY Laboratory Inc., USA) and photosynthetic photon flux density (PPFD) (LI-190SA, LI-COR Inc.) were measured at a height of $6 \mathrm{~m}$. Soil temperature (Campbell-107, Campbell Scientific Instruments Inc.) and moisture (CS616, Campbell Scientific Instruments Inc.) was measured at $0.02,0.04,0.1,0.2,0.4,0.8,1.2$ and $1.6 \mathrm{~m}$ depths. Three heat flux plates (HFT3, Campbell Scientific Instruments Inc.) were randomly buried at the depths of $0.01 \mathrm{~m}$. The average soil heat fluxes were calculated using the three randomly buried plates. These data were logged every $10 \mathrm{~min}$ by a digital micrologger (CR23X, Campbell Scientific Inc.) equipped with an analog multiplexer (AM416) used for sampling and logging data.

Daily soil evaporation was measured using three microlysimeters randomly placed between crop rows (one in the middle of the rows and the other two close to plants on each side of the rows). The microlysimeters with an internal diameter of $10 \mathrm{~cm}$ and a depth of $20 \mathrm{~cm}$ were filled with an intact soil core and pushed into soil with the top slightly above the soil surface (Daamen et al., 1993; Liu et al., 2002). The average weight loss of these microlysimeters measured using electronic scales with $0.01 \mathrm{~g}$ precision was nearly equal to soil evaporation. In order to keep the soil moisture in microlysimeters similar to that between the rows, the soil in the microlysimeters was replaced daily or every 2 days.
LAI was measured using the AM300 portable leaf area meter (ADC BioScientific Ltd., UK). The fraction of land cover $(f)$ was estimated by measuring the projected crop canopy area of selected stands in a corresponding field plot. LAI, $f$ and crop height were measured approximately every 10 days during the growing season, and the gaps were linearly interpolated to a daily interval.

\subsection{Description of the $S-W$ model}

In the $\mathrm{S}-\mathrm{W}$ model, the ecosystem evapotranspiration $(\lambda \mathrm{ET}$; $\mathrm{W} \mathrm{m}^{-2}$ ) is separated into evaporation from the soil surface $\left(\lambda E ; \mathrm{W} \mathrm{m}^{-2}\right)$ and transpiration from the vegetation canopy $\left(\lambda T ; \mathrm{W} \mathrm{m}^{-2}\right)$ (Fig. 2), which are calculated as (Shuttleworth and Wallace, 1985; Lhomme et al., 2012)

$\lambda \mathrm{ET}=\lambda E+\lambda T=C_{\mathrm{s}} \mathrm{ET}_{\mathrm{s}}+C_{\mathrm{c}} \mathrm{ET}_{\mathrm{c}}$,

$\mathrm{ET}_{\mathrm{s}}=\frac{\Delta A+\left[\rho C_{p} D-\Delta r_{\mathrm{a}}^{\mathrm{s}}\left(A-A_{\mathrm{s}}\right)\right] /\left(r_{\mathrm{a}}^{\mathrm{a}}+r_{\mathrm{a}}^{\mathrm{s}}\right)}{\Delta+\gamma\left[1+r_{\mathrm{s}}^{\mathrm{s}} /\left(r_{\mathrm{a}}^{\mathrm{a}}+r_{\mathrm{a}}^{\mathrm{s}}\right)\right]}$,

$\mathrm{ET}_{\mathrm{c}}=\frac{\Delta A+\left[\rho C_{p} D-\Delta r_{\mathrm{a}}^{\mathrm{c}} A_{\mathrm{s}}\right] /\left(r_{\mathrm{a}}^{\mathrm{a}}+r_{\mathrm{a}}^{\mathrm{c}}\right)}{\Delta+\gamma\left[1+r_{\mathrm{s}}^{\mathrm{c}} /\left(r_{\mathrm{a}}^{\mathrm{a}}+r_{\mathrm{a}}^{\mathrm{c}}\right)\right]}$,

$C_{\mathrm{s}}=\frac{1}{1+\left[R_{\mathrm{S}} R_{\mathrm{a}} / R_{\mathrm{c}}\left(R_{\mathrm{S}}+R_{\mathrm{a}}\right)\right]}$,

$C_{\mathrm{c}}=\frac{1}{1+\left[R_{\mathrm{c}} R_{\mathrm{a}} / R_{\mathrm{s}}\left(R_{\mathrm{c}}+R_{\mathrm{a}}\right)\right]}$,

$R_{\mathrm{a}}=(\Delta+\gamma) r_{\mathrm{a}}^{\mathrm{a}}$,

$R_{\mathrm{c}}=(\Delta+\gamma) r_{\mathrm{a}}^{\mathrm{c}}+\gamma r_{\mathrm{s}}^{\mathrm{c}}$,

$R_{\mathrm{s}}=(\Delta+\gamma) r_{\mathrm{a}}^{\mathrm{s}}+\gamma r_{\mathrm{s}}^{\mathrm{s}}$,

$\lambda E=\frac{\Delta A_{\mathrm{s}}+\rho C_{p} D_{0} / r_{\mathrm{a}}^{\mathrm{s}}}{\Delta+\gamma\left(1+r_{\mathrm{s}}^{\mathrm{s}} / r_{\mathrm{a}}^{\mathrm{s}}\right)}$,

$\lambda T=\frac{\Delta\left(A-A_{\mathrm{s}}\right)+\rho C_{p} D_{0} / r_{\mathrm{a}}^{\mathrm{c}}}{\Delta+\gamma\left(1+r_{\mathrm{s}}^{\mathrm{c}} / r_{\mathrm{a}}^{\mathrm{c}}\right)}$,

$D_{0}=D+\frac{(\Delta A-(\Delta+\gamma) \lambda \mathrm{ET}) r_{\mathrm{a}}^{\mathrm{a}}}{\rho C_{p}}$,

where $\mathrm{ET}_{\mathrm{S}}$ and $\mathrm{ET}_{\mathrm{c}}$ are terms to describe evaporation from soil and transpiration from the plant $\left(\mathrm{W} \mathrm{m}^{-2}\right)$, respectively; $C_{\mathrm{S}}$ and $C_{\mathrm{c}}$ are soil surface resistance and canopy resistance coefficients (dimensionless), respectively; $\lambda$ is the latent heat 


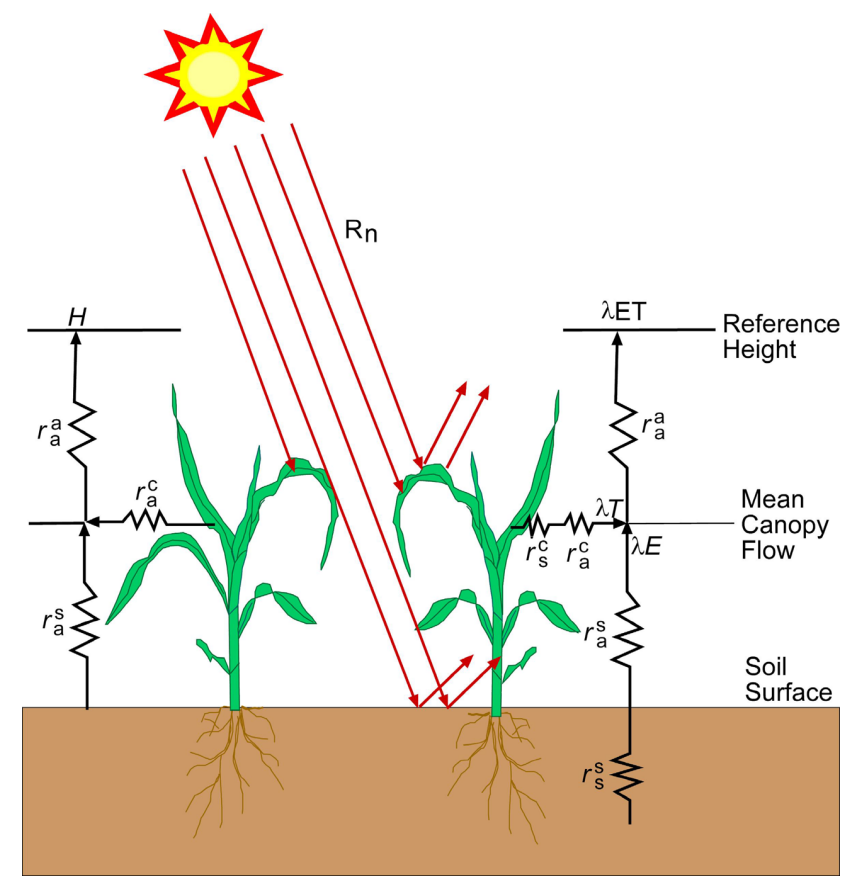

Figure 2. Schematic diagram of the $\mathrm{S}-\mathrm{W}$ model. From right to left, $r_{\mathrm{S}}^{\mathrm{c}}$ and $r_{\mathrm{a}}^{\mathrm{c}}$ are the bulk resistances of canopy stomatal and boundary layer $\left(\mathrm{s} \mathrm{m}^{-1}\right)$, respectively; $r_{\mathrm{a}}^{\mathrm{s}}$ and $r_{\mathrm{a}}^{\mathrm{a}}$ aerodynamic resistances from soil to canopy and from canopy to reference height $\left(\mathrm{s} \mathrm{m}^{-1}\right)$, respectively; $r_{\mathrm{s}}^{\mathrm{s}}$ soil surface resistance $\left(\mathrm{s} \mathrm{m}^{-1}\right) . \lambda T$ transpiration from canopy $\left(\mathrm{W} \mathrm{m}^{-2}\right), \lambda E$ evaporation from soil under plant $\left(\mathrm{W} \mathrm{m}^{-2}\right)$, and $\lambda$ ET total evapotranspiration $\left(\mathrm{W} \mathrm{m}^{-2}\right)$.

of evaporation $\left(\mathrm{J} \mathrm{kg}^{-1}\right) ; \Delta$ is the slope of the saturation vapor pressure versus temperature curve $\left(\mathrm{kPa} \mathrm{K}^{-1}\right) ; \rho$ is the air density $\left(\mathrm{kg} \mathrm{m}^{-3}\right) ; C_{p}$ is the specific heat capacity of dry air $\left(1013 \mathrm{~J} \mathrm{~kg}^{-1} \mathrm{~K}^{-1}\right) ; D$ and $D_{0}(\mathrm{kPa})$ are the air water vapor pressure deficit at the reference height $(3 \mathrm{~m})$ and the canopy height, respectively; $\gamma$ is the psychrometric constant $\left(\mathrm{kPa} \mathrm{K}^{-1}\right) ; r_{\mathrm{s}}^{\mathrm{c}}$ and $r_{\mathrm{s}}^{\mathrm{s}}$ are the surface resistance for plant canopy and soil surface $\left(\mathrm{s} \mathrm{m}^{-1}\right)$, respectively; $r_{\mathrm{a}}^{\mathrm{c}}$ and $r_{\mathrm{a}}^{\mathrm{s}}$ are aerodynamic resistances from the leaf to canopy height and soil surface to canopy height $\left(\mathrm{s} \mathrm{m}^{-1}\right)$, and $r_{\mathrm{a}}^{\mathrm{a}}$ is aerodynamic resistances from canopy height to reference height $\left(\mathrm{s} \mathrm{m}^{-1}\right)$. $A$ and $A_{\mathrm{s}}\left(\mathrm{W} \mathrm{m}^{-2}\right)$ are the available energy input above the canopy and above the soil surface, respectively, and are calculated as

$A=R_{\mathrm{n}}-G$,

$A_{\mathrm{s}}=R_{\mathrm{ns}}-G$,

where $R_{\mathrm{n}}$ and $R_{\mathrm{ns}}$ are net radiation fluxes into the canopy and the substrate $\left(\mathrm{W} \mathrm{m}^{-2}\right.$ ), respectively; $G$ is the soil heat flux $\left(\mathrm{W} \mathrm{m}^{-2}\right) . R_{\mathrm{ns}}$ was calculated using a Beer's law relationship of the form

$R_{\mathrm{ns}}=R_{\mathrm{n}} \exp \left(-K_{\mathrm{A}} \mathrm{LAI}\right)$, in which $K_{\mathrm{A}}$ is the extinction coefficient of light attenuation, This can be measured on site (see Sauer et al., 2007), and was set to be approximately 0.41 for spring maize (Mo et al., 2000).

The climate-related variables (i.e., $\lambda, e_{\mathrm{s}}, \Delta, \rho$ and $\gamma$ ) in Eqs. (1)-(3) are calculated by the formulas of Allen et al. (1998).

\subsection{Calculation of resistances in the S-W model}

The resistance network of the S-W model is shown in Fig. 2. In this paper, the three aerodynamic resistances (i.e., $r_{\mathrm{a}}^{\mathrm{a}}, r_{\mathrm{a}}^{\mathrm{c}}$ and $r_{\mathrm{a}}^{\mathrm{s}}$ ) were calculated using the same approach suggested by Shuttleworth and Wallace (1985), Shuttleworth and Gurney (1990) and Lhomme et al. (2012).

The canopy resistance $\left(r_{\mathrm{s}}^{\mathrm{c}}\right)$, which is the equivalent resistance of all the individual stomata in a canopy and depends on the environmental variables, can be calculated using the Jarvis-type model (Jarvis, 1976):

$r_{\mathrm{s}}^{\mathrm{c}}=\frac{r_{\mathrm{ST} m i n}}{2 \operatorname{LAI} \prod_{i} F_{i}\left(X_{i}\right)}$,

where $r_{\mathrm{STmin}}$ represents the minimal stomatal resistance of individual leaves under optimal conditions. $F_{i}\left(X_{i}\right)$ is the stress function of a specific environmental variable $X_{i}$, with $0 \leq F_{i}\left(X_{i}\right) \leq 1$. Following Stewart (1988) and Verhoef and Allen (2000), the stress functions were expressed as

$$
F_{1}\left(R_{\mathrm{S}}\right)=\frac{R_{\mathrm{S}}}{1000} \frac{1000+k_{1}}{R_{\mathrm{S}}+k_{1}}
$$

$$
\begin{aligned}
& F_{2}\left(T_{\mathrm{a}}\right)= \\
& \quad \frac{\left(T_{\mathrm{a}}-T_{\mathrm{a}, \min }\right)\left(T_{\mathrm{a}, \max }-T_{\mathrm{a}}\right)^{\left(T_{\mathrm{a}, \max }-k_{2}\right) /\left(k_{2}-T_{\mathrm{a}, \min }\right)}}{\left(k_{2}-T_{\mathrm{a}, \min }\right)\left(T_{\mathrm{a}, \max }-k_{2}\right)^{\left(T_{\mathrm{a}, \max }-k_{2}\right) /\left(k_{2}-T_{\mathrm{a}, \min }\right)},} \\
& F_{3}(D)=1-k_{3} D,
\end{aligned}
$$

$F_{4}\left(\theta_{\mathrm{r}}\right)= \begin{cases}1 & \theta_{\mathrm{r}}>\theta_{\mathrm{cr}} \\ \frac{\left(\theta_{\mathrm{r}}-\theta_{\mathrm{wp}}\right)}{\left(\theta_{\mathrm{cr}}-\theta_{\mathrm{wp}}\right)} & \theta_{\mathrm{wp}} \leq \theta_{\mathrm{r}} \leq \theta_{\mathrm{cr}} \\ 0 & \theta_{\mathrm{r}}<\theta_{\mathrm{wp}}\end{cases}$

where $k_{1}-k_{3}$ are constants (units see Table 1 ); $R_{\mathrm{S}}$ is the incoming solar radiation $\left(\mathrm{W} \mathrm{m}^{-2}\right) ; T_{\mathrm{a}}$ is the air temperature $\left({ }^{\circ} \mathrm{C}\right)$ at the reference height; $T_{\mathrm{a}, \min }$ and $T_{\mathrm{a}, \max }$ are the lower and upper temperatures limits $\left({ }^{\circ} \mathrm{C}\right)$, respectively, which are $T_{\mathrm{a}}$ values when $F_{2}\left(T_{\mathrm{a}}\right)=0$ and are set at values of 0 and $40^{\circ} \mathrm{C}$ (Harris et al., 2004); $\theta_{\mathrm{r}}$ is the actual volumetric soil

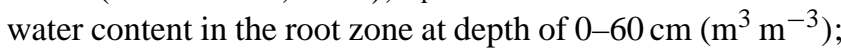
$\theta_{\mathrm{wp}}$ is water content at the wilting point $\left(\mathrm{m}^{3} \mathrm{~m}^{-3}\right)$; and $\theta_{\mathrm{cr}}$ is the critical water content $\left(\mathrm{m}^{3} \mathrm{~m}^{-3}\right)$ at which plant stress starts. The values of $\theta_{\mathrm{wp}}$ and $\theta_{\mathrm{cr}}$ are set as $0.11 \mathrm{~m}^{3} \mathrm{~m}^{-3}$ and 
Table 1. Prior distributions and the parameter bounds for the S-W model. These values are derived from the literature; the posterior parameter distribution estimated by MCMC is based on observed data in our site, and are characterized by the mean and $95 \%$ high-probability intervals (lower limit, upper limit).

\begin{tabular}{lllllll}
\hline & & \multicolumn{2}{c}{ Prior distribution } & & \multicolumn{2}{c}{ Posterior distribution } \\
\cline { 2 - 4 } Parameter & Lower bound & Upper bound & References & & Median & $95 \%$ High-probability interval \\
\hline$r_{\mathrm{STmin}}\left(\mathrm{s} \mathrm{m}^{-1}\right)$ & 0 & 80 & Noilhan and Planton (1989); Li et al. (2013a) & & $\mathbf{2 1 . 8}$ & $(20.2,24.6)$ \\
$k_{1}\left(\mathrm{~W} \mathrm{~m}^{-2}\right)$ & 0 & 500 & Stewart (1998) & & 294.6 & $(42.5,487.7)$ \\
$k_{2}\left({ }^{\circ} \mathrm{C}^{2}\right)$ & 5 & 40 & Ogink-Hendriks (1995) & & $\mathbf{2 5 . 6}$ & $(12.9,34.4)$ \\
$k_{3}\left(\mathrm{kPa}^{-1}\right)$ & 0 & 0.1 & Stewart (1998) & & 0.02 & $(0,0.07)$ \\
$b_{1}\left(\mathrm{~s} \mathrm{~m}^{-1}\right)$ & 4 & 15 & Sellers et al. (1992); Zhang (2012); Zhu et al. (2013) & $\mathbf{9 . 3}$ & $(8.4,10.0)$ \\
$b_{2}\left(\mathrm{~s} \mathrm{~m}^{-1}\right)$ & 0 & 8 & Sellers et al. (1992); Zhang (2012); Zhu et al. (2013) & $\mathbf{6 . 2}$ & $(3.8,7.4)$ \\
\hline
\end{tabular}

The bold number means that this parameter was well constrained by the data

$0.30 \mathrm{~m}^{3} \mathrm{~m}^{-3}$ for sandy loam in the study area (Zhao et al., 2010).

The soil surface resistance $\left(r_{\mathrm{s}}^{\mathrm{s}}\right.$; Fig. 2) was expressed as a function of near-surface soil water content (Sellers et al., 1992; Verhoef et al., 2006, 2012; Zhu et al., 2013):

$r_{\mathrm{s}}^{\mathrm{s}}=\exp \left(b_{1}-b_{2} \frac{\theta_{\mathrm{s}}}{\theta_{\mathrm{sat}}}\right)$,

in which $b_{1}$ and $b_{2}$ are empirical constants $\left(\mathrm{s} \mathrm{m}^{-1}\right) ; \theta_{\mathrm{s}}$ is soil water content in the top layer of soil (at depth of $2 \mathrm{~cm}$ ); and $\theta_{\text {sat }}$ is the saturated soil water content $\left(\mathrm{m}^{3} \mathrm{~m}^{-3}\right)$, which was estimated empirically through the near-surface soil texture. In summary, there are six site- and species-specific parameters that needed to be estimated in the S-W model associated with soil and canopy resistances, which are $b_{1}, b_{2}, r_{\mathrm{ST} \text { min }}$ and $k_{1}$ to $k_{3}$ (see Supplement 1).

\subsection{Bayesian inference framework and assimilation scheme}

With Bayes' theorem (a complete description was presented in Supplement 2), the posterior distribution of parameter $\boldsymbol{c}$ is generated by

$p(\boldsymbol{c} \mid \mathbf{O}) \propto p(\mathbf{O} \mid \boldsymbol{c}) p(\boldsymbol{c})$,

where $p(\boldsymbol{c})$ represents prior probability distributions of parameter $\boldsymbol{c}$, which is chosen as uniform distributions with specified allowable ranges (Table 1). In general, the parameter ranges were wide enough to include the actual parameter values and to give the optimization freedom. In the test study, we run the S-W model using 4000 parameter vectors which were sampled from the prior distribution using the Latin hypercube sampling (LHS) method (Iman and Helton, 1998), and found that the observed data in most cases were in the range of predicted values (Supplement 1); $p(\mathbf{O} \mid \boldsymbol{c})$ is the likelihood function, which reflects the influence of the observation data sets on parameter identification; and $p(\boldsymbol{c} \mid \mathbf{O})$ is the posterior distribution after Bayesian inference conditioned on available observations $\mathbf{O}$.

For each data set (e.g., $\lambda \mathrm{ET}$ and $E$ ), the modeldata mismatch $e_{i}(t)(i=1,2)$, which represents a relative "goodness-of-fit" measure for each possible parameter vector (van Oijen et al., 2011, 2013), is expressed by

$e_{i}(t)=O_{i}(t)-f_{i}(t)$,

where $O_{i}(t)$ and $f_{i}(t)$ are observed and modeled (Eqs. 1 or 9$)$ values of the $i$ th data set at time $t$, respectively. Assuming the model-data mismatch $e_{i}(t)$ follows a Gaussian distribution with a zero mean, the likelihood function for the $i$ th data set $\left(O_{i}(\cdot)\right)$ can be expressed by

$p\left(O_{i}(\cdot) \mid \boldsymbol{c}\right)=\prod_{t=1}^{n_{i}} \frac{1}{\sqrt{2 \pi} \sigma_{i}} e^{-\frac{\left(e_{i}(t)\right)^{2}}{2 \sigma_{i}^{2}}}$,

where $n_{i}$ is the number of observations of the $i$ th data set; and $\sigma_{i}(i=1,2)$ represents the residual errors, or standard deviation about model-predicted output of the $i$ th data set. Here, we assumed $\sigma_{i}$ is the same over the observation time for the $i$ th data set (Braswell et al., 2005). Traditionally, $\sigma_{i}$ can be included into the analysis explicitly (i.e., assuming $\sigma_{i}$ is uniform over $\log \sigma_{i}$; Gelman et al., 1995) and treated as one the model parameters, which yields a complete posterior distribution of $\sigma_{i}$. However, this method artificially increased the parameter dimension of the problem and may result in unreasonable estimations of the parameter values (Kavetski et al., 2006). In this study, $\sigma_{i}$ was estimated by using the analytical method (Hurtt and Armstrong, 1996; Braswell et al., 2005), which is to find the value of $\sigma_{i}$ that maximizes $\log \left(p\left(O_{i}(\cdot) \mid \boldsymbol{c}\right)\right)$ for a given parameter vector. By differentiating $\log \left(p\left(O_{i}(\cdot) \mid \boldsymbol{c}\right)\right)$ with respect to $\sigma_{i}$, we can obtain

$\sigma_{i}^{\mathrm{a}}=\sqrt{\frac{1}{n_{i}} \sum_{t=1}^{n_{i}}\left(e_{i}(t)\right)^{2}}$.

We then used $\sigma_{i}^{\text {a }}$ to replace $\sigma_{i}$ in Eq. (23).

The likelihood function for the multivariate data sets, $p(\boldsymbol{c} \mid \mathbf{O})$, used for parameter estimation is then defined as the product of the individual $p\left(O_{i}(\cdot) \mid \boldsymbol{c}\right)$ s (Richardson et al., 2010):

$p(\mathbf{O} \mid \boldsymbol{c})=\prod_{i=1}^{m} p\left(O_{i}(\cdot) \mid \boldsymbol{c}\right)=\prod_{i=1}^{m} \prod_{t=1}^{n_{i}} \frac{1}{\sqrt{2 \pi} \sigma_{i}} e^{-\frac{\left(e_{i}(t)\right)^{2}}{2 \sigma_{i}^{2}}}$, 
where $m$ is the number of data sets; When a particular data set $O_{i}(\cdot)$ was not being used in the optimization, we simply set the corresponding likelihood function $p\left(O_{i}(\cdot) \mid \boldsymbol{c}\right)$ to 1. Thus, this framework can be easily used when additional observations are available. In this study, the two data sets used to simultaneously optimize the parameter values were EC-measured half-hourly evapotranspiration $\left(\lambda \mathrm{ET} ; \mathrm{W} \mathrm{m}^{-2}\right)$ and microlysimeters-measured daily soil evaporation $(E$; $\mathrm{mm} \mathrm{day}^{-1}$ ).

\subsection{Metropolis-Hasting algorithm and convergence test}

The posterior distribution was sampled using the Metropolis-Hasting (M-H) algorithm (Metropolis et al., 1953; Hastings, 1970), a version of the Markov chain Monte Carlo (MCMC) technique. To generate a Markov chain in the parameter space, the $\mathrm{M}-\mathrm{H}$ algorithm was run by repeating two steps: a proposing step and a moving step. In the proposing step, a candidate point $\boldsymbol{c}^{\text {new }}$ is generated according to a proposal distribution $P\left(\boldsymbol{c}^{\mathrm{new}} \mid \boldsymbol{c}^{k-1}\right)$, where $c^{k-1}$ is the accepted point at the previous step. In the moving step, point $c^{\text {new }}$ is treated against the Metropolis criterion to examine if it should be accepted or rejected. It was well recognized that the efficiency of the $\mathrm{M}-\mathrm{H}$ algorithm was strongly effected by the proposal distribution function. To find an effective proposal distribution $P\left(c^{\text {new }} \mid c^{k-1}\right)$, a test run of the M-H algorithm with 10000 simulations was made by using a uniform proposal distribution (Braswell et al., 2005):

$\boldsymbol{c}^{\mathrm{new}}=\boldsymbol{c}^{k-1}+r\left(\boldsymbol{c}^{\mathrm{max}}-\boldsymbol{c}^{\mathrm{min}}\right)$,

where $\boldsymbol{c}^{k-1}$ is the current accepted point, $r$ is a random number uniformly distributed between -0.5 and +0.5 , and $c^{\mathrm{min}}$ and $\boldsymbol{c}^{\mathrm{max}}$ are the lower and upper limits of parameter vector $\boldsymbol{c}$ (Table 1). Based on the test run, we then constructed a normal proposal distribution $c^{\text {new }} \sim N\left(c^{(k-1)}, \operatorname{cov}^{0}(\boldsymbol{c})\right)$, where $\operatorname{cov}^{0}(\boldsymbol{c})$ is the covariance matrix of the parameter vector $\boldsymbol{c}$ from the initial test run (Xu et al., 2006). The detailed description of the MCMC sampling procedure and the code written in MATLAB were presented in Supplement 2.

We ran at least four parallel MCMC chains with 20000 iterations each, evaluated the chain convergence using the Gelman-Rubin (G-R) diagnostic method (Gelman and Rubin, 1992) (Supplement 3), and thinned the chains (every 20th iteration) when appropriate to reduce within chain autocorrelation, thereby producing an independent sample of 3000 values for each parameter from the joint posterior distribution.

\subsection{Evaluation of model output estimates}

Since the primary interest in application of the S-W model was to reproduce the pattern of water vapor fluxes from different sources (i.e., soil and vegetation) during the whole study period, we used all available data to construct the likelihood function (Eq. 25) and to obtain the posterior distribution of the parameters. Then, the performance of the S-W model was evaluated using the coefficient of determination of the linear regression between measured and estimated values of water vapor fluxes, $R^{2}$, representing how much the variation in the observations was explained by the models. Also, the root mean square error (RMSE), mean bias error (MBE), index of agreement (IA) and model efficiency (EF) (Legates and McCabe, 1999; Poblete-Echeverria and OrtegaFarias, 2009) were included in the statistical analysis, which are calculated as follows:

$$
\begin{aligned}
& \mathrm{RMSE}=\sqrt{\frac{1}{n_{i}} \sum_{t=1}^{n_{i}}\left[O_{i}(t)-f_{i}(t)\right]^{2},} \\
& \mathrm{MBE}=\frac{1}{n_{i}} \sum_{t=1}^{n_{i}}\left[O_{i}(t)-f_{i}(t)\right], \\
& \mathrm{IA}=1-\frac{\sum_{t=1}^{n_{i}}\left[O_{i}(t)-f_{i}(t)\right]^{2}}{\sum_{t=1}^{n_{i}}\left[\left|O_{i}(t)-\overline{O_{i}}\right|+\left|f_{i}(t)-\overline{O_{i}}\right|\right]^{2}}, \\
& \mathrm{EF}=1-\frac{\sum_{t=1}^{n_{i}}\left[O_{i}(t)-f_{i}(t)\right]^{2}}{\sum_{t=1}^{n_{i}}\left[O_{i}(t)-\overline{O_{i}}\right]^{2}},
\end{aligned}
$$

where $n_{i}$ is the total number of observations of the $i$ th data set $O_{i}(t)$ is the observed values at time $t$ of the $i$ th data set, $\overline{O_{i}}$ is the mean of the observed value of the $i$ th data set, and $f_{i}(t)$ is the simulation which was calculated using the posterior median parameter values, and other parameter vectors selected from the parameter chains generated by the MCMC iteration (van Oijen et al., 2013).

\section{Results}

\subsection{Environmental and biological factors}

Detailed information on the seasonality of key environmental and biological variables is essential to assess seasonal variation in the actual ET and its partitioning. The seasonal change in net solar radiation $\left(R_{\mathrm{n}} ; \mathrm{MJ} \mathrm{m}^{-2} \mathrm{day}^{-1}\right)$, air temperature $\left(T_{\mathrm{a}} ;{ }^{\circ} \mathrm{C}\right)$, air water vapor pressure deficit $(D ; \mathrm{kPa})$, wind speed $\left(u ; \mathrm{m} \mathrm{s}^{-1}\right)$ at the height of $3 \mathrm{~m}$, rainfall and irrigation $(\mathrm{mm})$, soil water content $\left(\theta ; \mathrm{m}^{3} \mathrm{~m}^{-3}\right)$, and leaf area in$\operatorname{dex}\left(\mathrm{LAI} ; \mathrm{m}^{2} \mathrm{~m}^{-2}\right)$ are illustrated in Fig. 3. During the study period (DOY (day of year) $147-257$ ), the daily mean $R_{\mathrm{n}}$ varied from 2.6 to $18.5 \mathrm{MJ} \mathrm{m}^{-2}$ day $^{-1}$ with an average value of $11.9 \mathrm{MJ} \mathrm{m}^{-2} \mathrm{day}^{-1}$. The peaked values were recorded from 

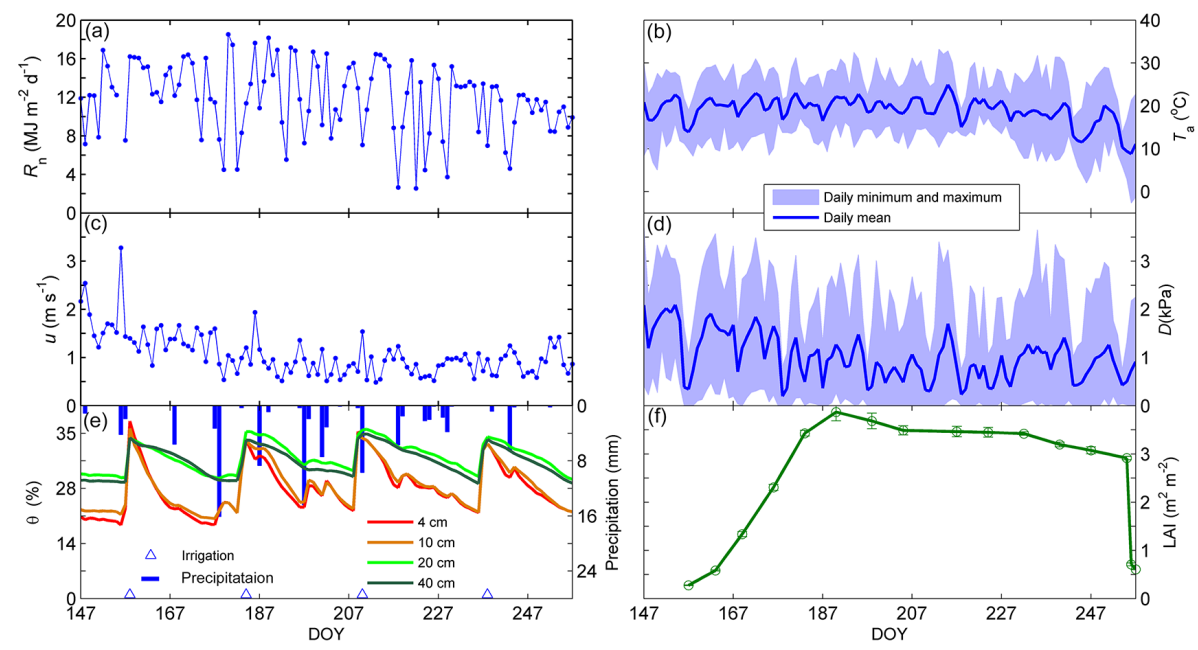

Figure 3. Seasonal variation in (a) $R_{\mathrm{n}}\left(\mathrm{MJ} \mathrm{m}^{-2} \mathrm{day}^{-1}\right)$, (b) $T_{\mathrm{a}}\left({ }^{\circ} \mathrm{C}\right),(\mathbf{c}) D(\mathrm{kPa}),(\mathbf{d}) u\left(\mathrm{~m} \mathrm{~s}^{-1}\right)$ at the height of $3 \mathrm{~m}$, (e) precipitation and irrigation (mm), $\theta\left(\mathrm{m}^{3} \mathrm{~m}^{-3}\right)$ at 4, 1020 and $40 \mathrm{~cm}$ depth, and (f) LAI $\left(\mathrm{m}^{2} \mathrm{~m}^{-2}\right)$ during the study period in the Daman Oasis.

the end of June to the middle of July (DOY 180-195). The variation of mean daily $T_{\mathrm{a}}$ has a similar trend to $R_{\mathrm{n}}$, varying from 8.8 to $24.9^{\circ} \mathrm{C}$ with an average value of around $19.0^{\circ} \mathrm{C}$. $D$ exhibited large diurnal variation ranging from 0 to $3.5 \mathrm{kPa}$, and the daily mean $D$ was relatively small when the LAI was larger than $3 \mathrm{~m}^{2} \mathrm{~m}^{-2}$ (DOY 197-230). Daily mean $u$ ranged from 0.5 to $3.2 \mathrm{~m} \mathrm{~s}^{-1}$, and was close to normal longterm values. Total precipitation during the study period was $104.2 \mathrm{~mm}$ with eight events over $5.0 \mathrm{~mm}$ (Fig. 3). $\theta$ varied greatly over the whole growing season. The variability of $\theta$ mainly depended on the irrigation scheduling by the local government (irrigation quota and timing). Soil water content had a peak value (about $0.35 \mathrm{~m}^{3} \mathrm{~m}^{-3}$ ) after irrigation and gradually reduced till the next irrigation (Fig. 3). The LAI showed a clear "one peak" pattern over the whole growing season with relatively high values of $3.5 \mathrm{~m}^{-2} \mathrm{~m}^{-2}$ from early July to late August (DOY 184-221).

\subsection{Posterior distribution of S-W model parameters}

The posterior parameter distributions are shown as histograms in Fig. 4 and summarized in Table 1 by posterior medians and $95 \%$ probability intervals. The results showed that the Bayesian calibration against the multivariate data sets was in most cases successful in reducing the assumed prior ranges of the parameters values. Parameters $r_{\mathrm{STmin}}, b_{1}, b_{2}$ and $k_{2}$ showed relatively large uncertainty reductions (defined as $1-\mathrm{CI}_{\text {posterior }} / \mathrm{CI}_{\text {prior }}$, where $\mathrm{CI}$ is the length of the $95 \%$ credible interval) (Fig. 5), and their posterior distributions became approximately symmetric with distinctive modes, while parameters $k_{1}$ and $k_{3}$ have relatively large variability (widely spread on the prior bounds) (Fig. 4). The global sensitivity analysis with the first-order impact ratio (FOIR) values (Supplement 1) reveals the importance of input parameters in affecting total ecosystem
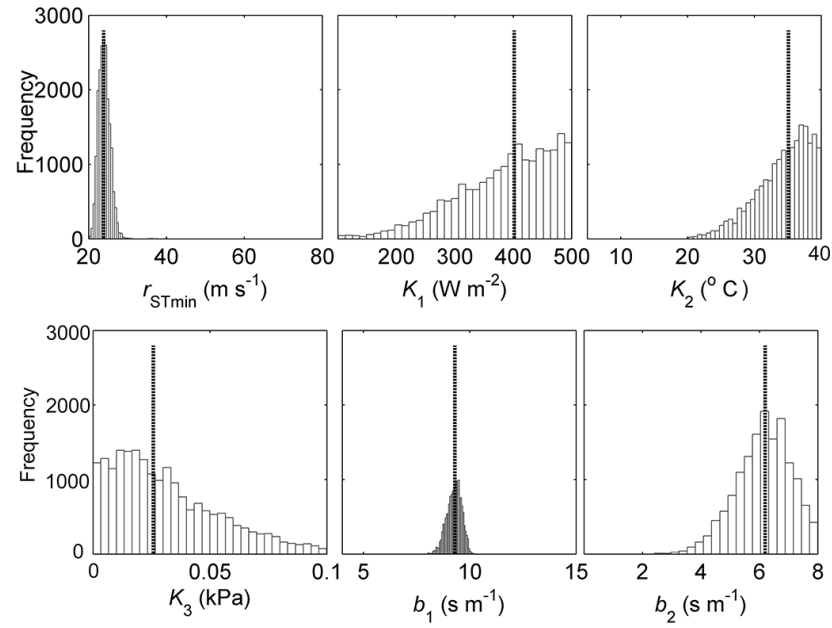

Figure 4. Histograms of samples from the posterior distributions of the parameters. The dashed vertical lines indicate median parameter values.

evapotranspiration. The results indicated that total ET responded sensitively to $r_{\mathrm{STmin}}, b_{1}, b_{2}$ and $k_{2}$ with FOIR values being 54.3, 21.9, 10.4 and $8.5 \%$ (Supplement 1), respectively. Other parameters exhibit relatively low $(<5 \%)$ FOIR values, suggesting that the variability in these parameters had almost no effect on the variability in model output. It is worth noting that the four highest sensitive parameters $\left(r_{\mathrm{STmin}}, b_{1}\right.$, $b_{2}$ and $k_{2}$ ) also corresponded to the greatest degree of updating in the Bayesian inference. Thus, we thought that the key parameters in the $\mathrm{S}-\mathrm{W}$ model were well optimized by the Bayesian method against the multivariate data sets. In addition, the correlation coefficient between the posterior distribution of parameters can be used to find groups of parameters that tend to be constrained together (Knorr and Kattge, 


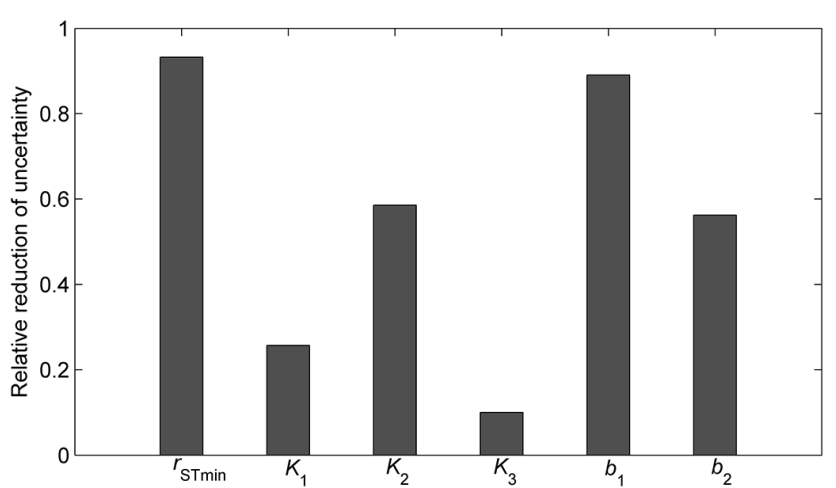

Figure 5. Relative uncertainty reductions in the length of $95 \%$ credible interval form prior to posterior distribution.

2005). In this study, the six calibrated parameters were not significantly intercorrelated with each other with correlation coefficients lower than 0.1 (Supplement 2).

The responses of soil surface resistances $\left(r_{\mathrm{s}}^{\mathrm{s}}\right)$ to soil water content computed using our posterior mean $b_{1}$ and $b_{2}$ values were very similar to that calculated using equation developed by Ortega-Farias et al. (2010) based on direct soil evaporation measurements, but seemed to be more sensitive to changes in soil water content compared with some other studies (e.g., Sun, 1982; Sellers et al., 1992; Zhu et al., 2013; Fig. 6). When just using EC-measured $\lambda$ ET data, a relatively wider posterior distribution of $b_{2}$ was observed (see Supplement 2). Thus, the daily soil evaporation data helped to well constrain estimates of $b_{1}$ and $b_{2}$. The posterior mean value of $r_{\text {STmin }}$ from our study was very close to that $\left(20 \mathrm{~s} \mathrm{~m}^{-1}\right)$ reported for spring maize growing in northwestern China obtained by using the least squares fitting method (Li et al., 2013a). The variations of the minimal stomatal resistance $\left(r_{\mathrm{STmin}}\right)$ for many natural and cultivated plants have been widely investigated by previous studies (Korner et al., 1979; Pospisilova and Solarova, 1980). Typical values for $r_{\text {STmin }}$ vary considerably from about $20-100 \mathrm{~s} \mathrm{~m}^{-1}$ for crops to $200-300 \mathrm{~s} \mathrm{~m}^{-1}$ for many types of trees. Thus, our results fell within the range of previous studies. However, some parameters related to canopy surface resistance (i.e., $k_{1}$ and $k_{3}$ ) seemed to be not well updated (Fig. 4). This may be due to the fact that these parameters may be insensitive to the present available data sets.

\subsection{Model performance compared with measurements}

Having parameterized the S-W model as described above, we ran the model to simulate the half-hourly $\lambda \mathrm{ET}$ (Eq. 1) and $\lambda E$ (Eq. 9) values $\left(\mathrm{W} \mathrm{m}^{-2}\right.$ ). The daily estimations of evapotranspiration $\left(\mathrm{ET} ; \mathrm{mm} \mathrm{day}^{-1}\right)$ and soil evaporation $(E$; $\mathrm{mm} \mathrm{day}^{-1}$ ) were obtained by summing up the half-hourly simulated values. The statistical analysis of observed versus estimated values of water vapor fluxes at different timescales are summarized in Table 2. These results indicated that the

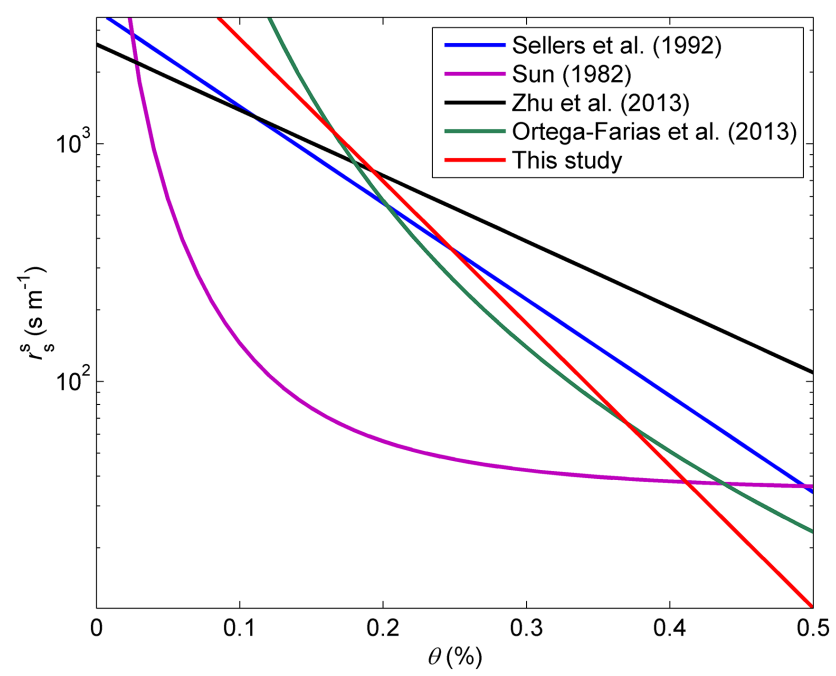

Figure 6. Comparisons of responses of soil surface resistance $\left(r_{\mathrm{s}}^{\mathrm{s}}\right.$; $\left.\mathrm{s} \mathrm{m}^{-1}\right)$ to soil surface water content $(\theta ; \%)$.

parameterized $\mathrm{S}-\mathrm{W}$ model was able to predict $\lambda \mathrm{ET}$ on a halfhourly basis with values of $R^{2}$, IA and EF equal to $0.83,0.93$ and 0.74 , respectively. However, significant differences exist between measured and modeled half-hourly $\lambda \mathrm{ET}$ values for the spring maize in the arid desert oasis. The slope (0.84) of the regression equation between the measured and modeled half-hourly $\lambda$ ET values was lower than 1 (Table 2, Fig. 7a), which indicated that the S-W model tended to underestimate the half-hourly $\lambda$ ET with a MBE value of $24.2 \mathrm{~W} \mathrm{~m}^{-2}$. Ortega-Farias et al. (2010) also reported that the S-W model underestimated on half-hourly time intervals compared to the EC-measured $\lambda \mathrm{ET}$ over a drip-irrigated vineyard in a Mediterranean semiarid region during the growing season in 2006. On the contrary, some studies showed that the S-W model overestimated half-hourly $\lambda$ ET (e.g., Li et al., 2013a; Ortega-Farias et al., 2007; Zhang et al., 2008). Therefore, the performance of the S-W model seemed to be variable for different crops and places, and there is a need to identify the causes that induced the disagreements between observed and modeled values (discussed below).

The fluctuation of measured and estimated daily ET and $E$ is illustrated in Fig. 8. In this case, a good agreement between measured and estimated daily $E$ was obtained with values of $R^{2}$, IA and EF equal to 0.82, 0.94 and 0.76 (Table 2). The points in plots of measured-versus-modeled daily $E$ fell tightly along the $1: 1$ line (slope $=1.01$ and intercept $=0.01$ with $\mathrm{RMSE}=0.05$ and $\mathrm{MBE}=-0.01$; Fig. $7 \mathrm{~b}$, Table 2). Also, the $95 \%$ posterior prediction intervals of simulated soil $E$ was narrow. Thus, we thought that the soil resistance in the S-W model was properly parameterized for the spring maize by the measured soil evaporation data. From Fig. 8, we can also observe that the estimated daily ET generally fluctuated tightly with the measured values with relative narrow uncertainties ( $95 \%$ posterior predication intervals). The values of 
Table 2. Statistical analysis of measured and estimated, using the median parameter values, half-hourly evapotranspiration $\left(\lambda \mathrm{ET}\right.$; $\left.\mathrm{W} \mathrm{m}^{-2}\right)$, daily soil evaporation $\left(E ; \mathrm{mm} \mathrm{day}^{-1}\right)$, and daily evapotranspiration (ET; mm day $\left.{ }^{-1}\right)$ for the spring maize in arid desert oases during the study period.

\begin{tabular}{|c|c|c|c|c|c|c|c|c|c|}
\hline & $n$ & $\begin{array}{l}\text { Regressive } \\
\text { equation }\end{array}$ & $R^{2}$ & $\begin{array}{r}\text { Mean } \\
\text { measured } \\
\text { values }\end{array}$ & $\begin{array}{r}\text { Mean } \\
\text { simulated } \\
\text { values }\end{array}$ & RMSE & MBE & IA & $\mathrm{EF}$ \\
\hline$E\left(\mathrm{~mm} \mathrm{day}^{-1}\right)$ & 56 & $E_{\text {modeled }}=1.01 E_{\text {measured }}+0.01$ & 0.82 & 0.26 & 0.28 & 0.05 & -0.01 & 0.94 & 0.76 \\
\hline $\mathrm{ET}\left(\mathrm{mm} \mathrm{day}^{-1}\right)$ & 95 & $\mathrm{ET}_{\text {modeled }}=0.83 \mathrm{ET}_{\text {measured }}+0.19$ & 0.83 & 2.02 & 1.88 & 0.32 & 0.14 & 0.94 & 0.79 \\
\hline
\end{tabular}

$n$ is the sample number; $R^{2}$ is the determination coefficient; RMSE is the root mean square error; MBE is mean bias error between measured and modeled values; IA is the index of agreement; ET is model efficiency. These statistical parameters are calculated using formulas given by Legates and McCabe (1999) and Poblete-Echeverria and Ortega-Farias (2009).

RMSE, MBE, IA and EF were equal to $0.05,0.14 \mathrm{~mm} \mathrm{day}^{-1}$, 0.94 and 0.79 , respectively (Table 2). However, there are 12 days during the study period (111 days) with observations beyond the upper boundary of the $95 \%$ posterior predication intervals (Fig. 8). For example, on 5 July, the estimated, using the median values of the parameters, and measured daily ETs were 2.9 and $4.3 \mathrm{~mm} \mathrm{day}^{-1}$, respectively (Fig. 8). Thus, the causes of the underestimations of ET by the S-W model on these days needs to be carefully checked based on detailed micrometeorological data. This work would help us to modify the model in a correct way and improve the precision of prediction.

\subsection{Identification of the disagreement/agreement between observed and modeled ET values}

The diurnal variation of $R_{\mathrm{n}}, H$ and $\lambda \mathrm{ET}$ (measured and modeled) above the spring maize ecosystem for some selected days is presented in Fig. 9. The uncertainties of $H$ and $\lambda \mathrm{ET}$ increased with the flux magnitude (Fig. 9), and tended to be approximately 14 and $13 \%$, respectively (Wang et al., 2014). The relative error for $R_{\mathrm{n}}$ was relatively small and estimated to be $1.24 \%$ (Xu et al., 2013). Resulting from the high surface heterogeneities, one special phenomenon, known as the "oasis effect" (Lemon et al., 1957; Oke, 1978) or "cold island effect" (Wang and Mitsuta, 1992; Zhang and Huang, 2004), was often observed on clear days in July and August in the study area and it is characterized as follows: (1) $H$ is very small and even negative (downward) in the afternoon (Fig. 9a-c) due to the microscale advection of hot dry air over the desert to the crop's surface in the oasis (Oke, 1978; Hu, 1994). For example, on 5 July, $H$ was continuously negative from 12:00 to 20:00 BST (Beijing standard time) (Fig. 9a). A strong advection process can be distinctly detected from the temperature and relative humidity profiles (Fig. 10a, b), in which the highest temperature occurred at a height of 8 $18 \mathrm{~m}$. (2) Measured actual $\lambda E T$ often exceeded (Fig. 9a) or was equal to (Fig. 9b, c) the local net radiation because of the added energy in the form of downward fluxes of $H$ to the ET process (Evett et al., 2012). Under such conditions, the S-W
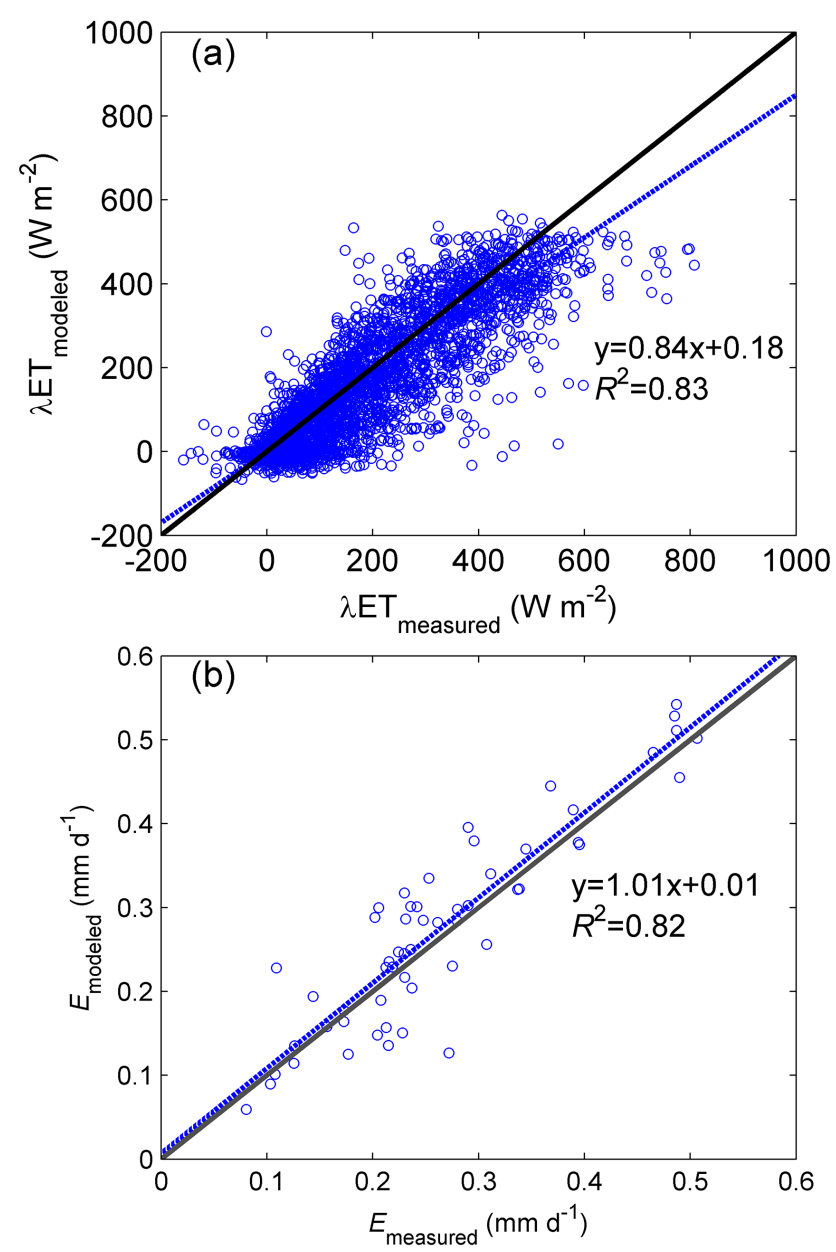

Figure 7. (a) Plot of estimated evapotranspiration $\left(\lambda \mathrm{ET} ; \mathrm{W} \mathrm{m}^{-2}\right)$ against observed values. The regressions is $y=0.84 x+0.18\left(R^{2}=\right.$ $0.83)$; (b) Plot of estimated daily soil evaporation $\left(E ; \mathrm{mm} \mathrm{day}^{-1}\right)$ against measured data. The regressions is $y=1.01 x+0.01\left(R^{2}=\right.$ $0.82)$.

model significantly underestimated the actual ET values due to the real atmospheric flows that do not correspond to its assumption of horizontal homogeneities (Rao et al., 1974). 


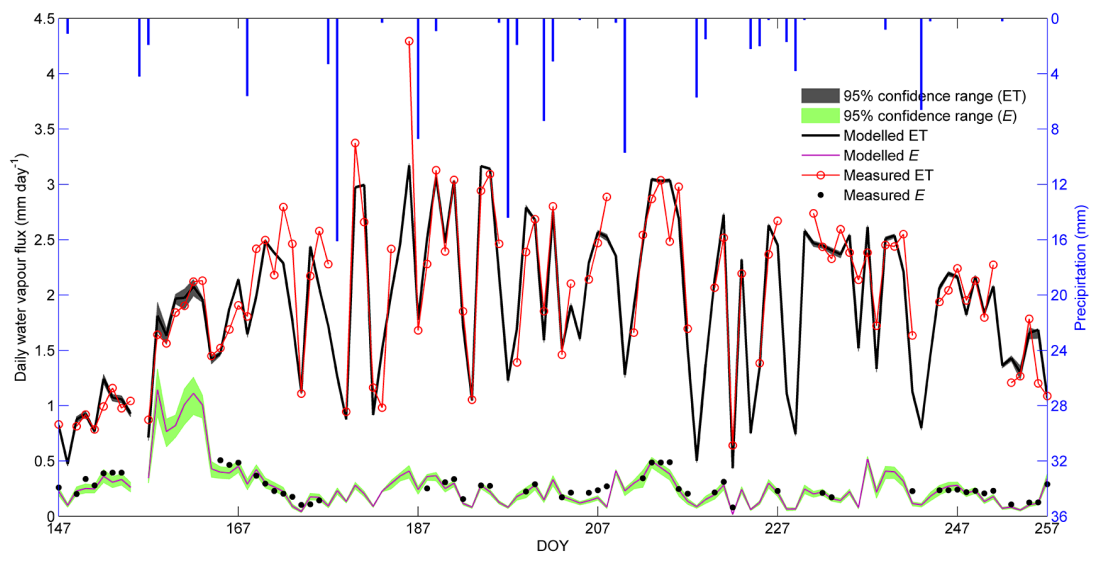

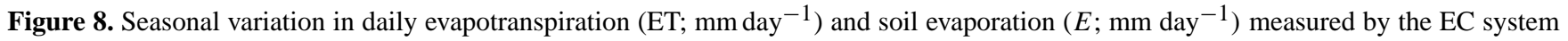
and modeled by the S-W model during the study period in the Daman Oasis. A gap in the time series is caused either by the absence of flux measurements or missing ancillary data.
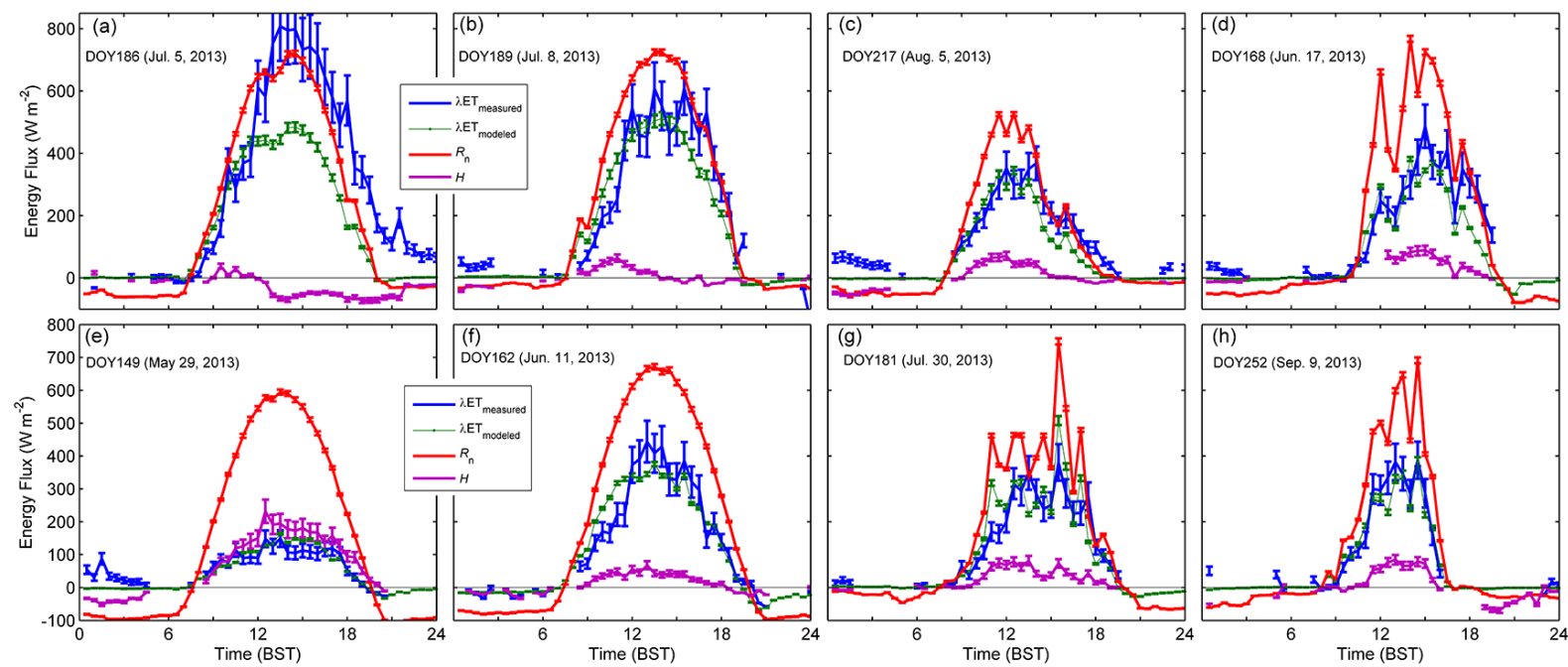

Figure 9. Diurnal variations in $R_{\mathrm{n}}\left(\mathrm{W} \mathrm{m}^{-2}\right), H\left(\mathrm{~W} \mathrm{~m}^{-2}\right)$, and modeled and measured evapotranspiration flux $\left(\lambda \mathrm{ET} ; \mathrm{W} \mathrm{m}{ }^{-2}\right)$. (a-c) represent conditions at which microscale advection occurred at 12:00, 15:00 and 17:00 BST, respectively, (d) represents a rainy day, and (e-h) represent clear and advection-absent days during the study period. A gap is caused either by the absence of flux measurements or missing ancillary data. Modeled $\lambda E T$ was presented as median $\pm 95 \%$ posterior predication intervals.

Thus, to properly represent the advection process in the SW model, special attention should be paid in simulating ET over crop ecosystems in arid desert oases in future studies. In addition to this situation, slight underestimations were also observed on or shortly after rainy days (Fig. 8). For example, the simulated half-hourly $\lambda \mathrm{ET}$ was lower than that measured by EC after the rainfall event occurred at 13:00 BST on 17 June (Fig. 9d). We thought that the underestimations by the model on or shortly after rainy days were mainly due to ignoring the direct evaporation of liquid water intercepted in the crop canopy, because no downward $H$ and temperature inversion were observed on this day (Fig. 10c, d). Until now, several canopy interception models have been developed (e.g., Rutter et al., 1971; Mulder, 1985; Gash et al.,
1995; Bouten et al., 1996). However, many of them were developed for simulating the rainfall interception by forest ecosystems, and their suitability for crops need to be further investigated.

The diurnal variation of simulated half-hourly $\lambda \mathrm{ET}$ by the parameterized S-W model has a similar trend to the measurements on clear and advection-absent days during the whole study period (Fig. 9e-h). On these days, $H$ was positive (upwards) at day time (Fig. 9e-h) and no temperature inversion was observed (Fig. 10e, f). Thus, we thought that the parameterization schedule adopted in this study worked well. It also demonstrated that the properly parameterized S-W model can be used in simulating and partitioning ET for homogeneous land surfaces. Hu et al. (2009) reported that the 


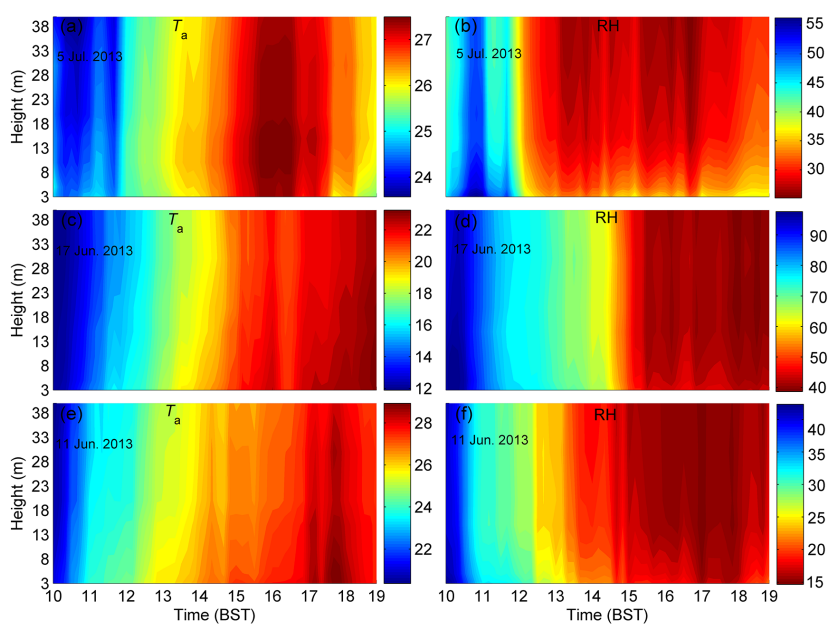

Figure 10. The diurnal evolutions of temperature $\left(T_{\mathrm{a}} ;{ }^{\circ} \mathrm{C}\right)$ and relative humidity (RH; \%) profiles from 3 to $40 \mathrm{~m}$ above the ground on 5 July 2013 (a). An obvious advection process can be detected from 13:00 to 17:00 BST with high temperature and a low RH layer at the height of $8-18 \mathrm{~m}$ on 17 June 2013 (b). A precipitation event occurred at 13:00 BST and resulted in uniform vertical distributions of $T_{\mathrm{a}}$ and $\mathrm{RH}$, but no temperature inversion was observed on 11 June 2013 (c). It represented a typical clear and advection-absent day.

S-W model parameterized by using the Monte Carlo method can successfully simulate ET at four uniform grasslands in China; our previous studies (Zhu et al., 2013) also illustrated that the parameterized S-W model can be used to simulate and partition ET over a vast alpine grassland in the QinghaiTibet Plateau.

\section{Discussion}

The assessment of model errors remains an outstanding challenge in hydrology (Beven et al., 2008). Identifying the uncertainties related to model parameters and structure needs to have a prominent position in hydrological modeling (Bastola et al., 2011; Brigode et al., 2013). An important issue in identifying the parameter uncertainty is equifinality, where different parameters of the same model yield similar results, making it difficult to distinguish which is correct (see Franks et al., 1997). A variety of recent studies corroborated that the multi-objective calibration against the multiple (orthogonal; see Winsemius et al., 2006) data sets can produce robust parameter estimates (e.g., Engeland et al., 2006; Fenicia et al., 2007; Moussa and Chahinian, 2009; Richardson et al., 2010; Hrachowitz et al., 2013a). In this study, we constructed a Bayesian inference framework to constrain the model parameters using the EC-measured ET and microlysimetersmeasured daily $E$ data sets simultaneously. The results indicated that four of the six main parameters were considerably updated, and simulated $\lambda \mathrm{ET}$ and $E$ were comparable to
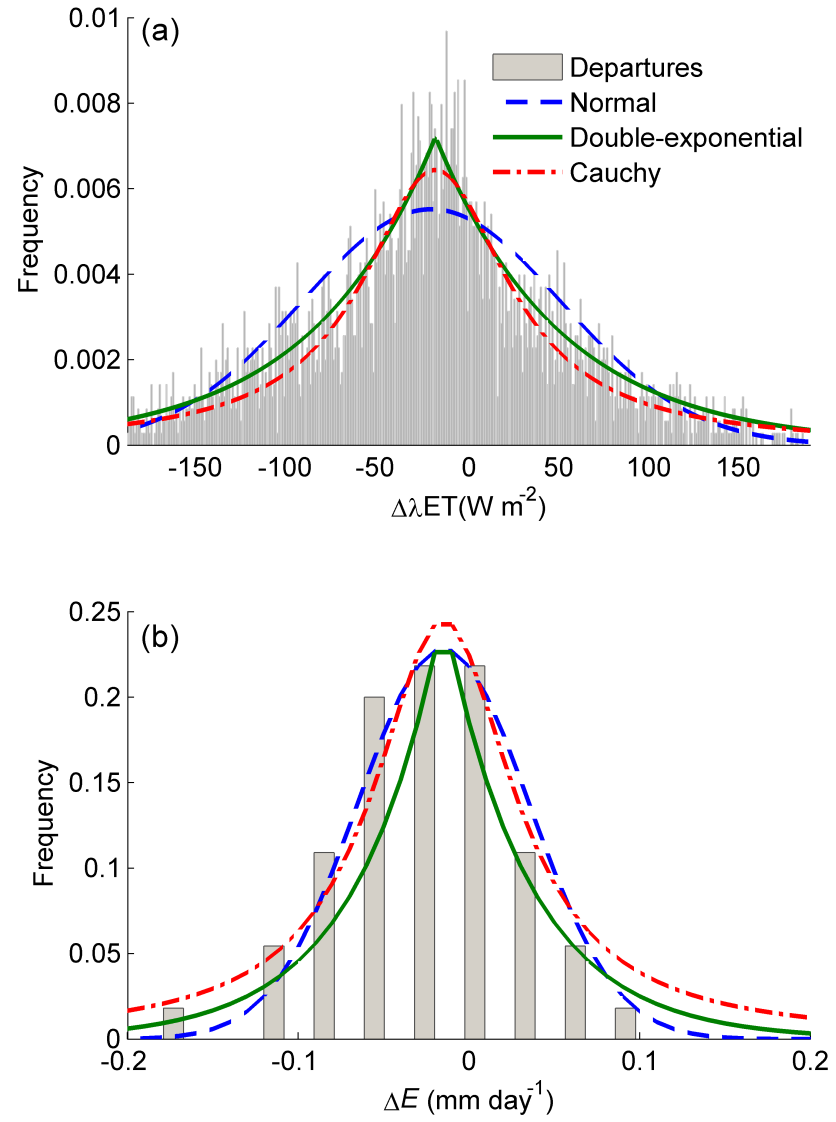

Figure 11. Histograms depicting the frequency distribution of the model-minus-observation departures for (a) half-hourly $\lambda \mathrm{ET}$ $\left(\mathrm{W} \mathrm{m}^{-2}\right)$ and (b) daily soil evaporation $E\left(\mathrm{~mm} \mathrm{day}^{-1}\right)$.

the measurements with relatively narrow uncertainties $(95 \%$ posterior predication intervals). Using just EC-measured ET data in our test study (see Supplement 2), the optimized S$\mathrm{W}$ model on the simulations of $\lambda \mathrm{ET}$ were not significantly different from that optimized by the multivariate data sets procedure, but it significantly underestimated $E$ with great uncertainties (Supplement 2). Thus, we can not ensure that the S-W model, optimized using only the EC-measured ET data, can properly partition the total ET into its different components (soil evaporation and plant transpiration), even thought the simulated $\lambda \mathrm{ET}$ values were in good agreement with measurements. Limited success in estimating processbased model parameters using EC-measured data alone were also reported in previous studies (e.g., Wang et al., 2001; Knorr and Kattge, 2005; Richardson et al., 2010).

With the developments of observation technologies and strategies, major steps forwards have been made in extracting a wide variety of environmental data (Hrachowitz et al., 2013b). Thus, it is critical to assess to what extent the uncertainty in model parameters and model predictions is reduced by the use of additional data and what new observation is required. The Bayesian inference framework used in 
this study provided a convenient way to simultaneously constrain model parameters when the new observation data sets are available. However, even with all data sets (EC-measured $\lambda$ ET and microlysimeters-measured daily $E$ ), some parameters related to canopy surface resistance seemed to be not well updated (Fig. 4). We thought that this may be due to the insensitivity of these parameters (e.g., $k_{1}, k_{3}, T_{\mathrm{amax}}, T_{\mathrm{amin}}$ and $K_{\mathrm{A}}$ ) to the present available data sets. Thus, direct observations of plant transpiration using sap flow or stable isotope $\left(\delta^{2} \mathrm{H}\right.$ and $\left.\delta^{18} \mathrm{O}\right)$ technologies (see Williams et al., 2004), canopy temperature using infrared thermometer and continuous within- and above-canopy radiation using the fourcomponent net radiometer (see Sauer et al., 2007) are needed in the future studies.

The method, as implemented here, used all observations simultaneously to constrain parameters and obtain an optimal match between data and model. After parameter optimization, the main source of model error can be attributed to the model structure. Thus, this method facilitates the detection of the model's structural failures. Until now, numerous models, retaining the $\mathrm{S}-\mathrm{W}$ model as basis, have been developed for estimating ET or its different components, and they tended to be more and more complex (see Lhomme et al., 2012). However, increasing model complexity is always accompanied by a great danger of equifinality and large uncertainties in forward runs (Beven, 1989; Franks and Beven, 1997). Most importantly, we must ensure that we are on the right direction in modifying the model. In this study, we found that the S-W model applied in arid areas generally failed when local advection occurred (Fig. 9). Thus, we thought that the main structural error of the S-W model as well as its various extensions comes from the ignorance of the effects of advection on the ET processes. A potential solution is to add the additional energy (negative $H$ ) to the available energy term defined in Eq. (12) (see Parlange and Katul, 1992).

The distribution of the model-minus-observation residuals, through the likelihood function, may also have an influence on the estimation of posterior parameter distributions (Raupach et al., 2005). However, a priori assessment of these errors may be not easy (Beven, 2001). Figure 11 shows the distribution of the residuals between simulated and observed data sets. The results indicated that the model-minusobservation departures of half-hourly $\lambda \mathrm{ET}$ flux was better approximated by a double-exponential distribution, which was in agreement with previous studies (Hollinger and Richardson, 2005; Richardson et al., 2006). Thus, the two-tower approach (Hollinger and Richardson, 2005), which can give a prior estimate of the flux data uncertainties, should be applied in the Bayesian inference in future studies. The Cauchy distribution gave a more appropriate approximation for the daily $E$ departures. However, the Cauchy distribution may be not a good choice for the purpose of Bayesian inference, since its first four moments are undefined (Richardson et al., 2008).

\section{Conclusions}

This study illustrated the use of the Bayesian method to simultaneously parameterize a two-source ET model against the multivariate data sets for a crop ecosystem in a desert oasis of northwestern China. The posterior distributions of the model parameters in most cases can be well constrained by the observations. Generally, the parameterized model has a good performance in simulating and partitioning ET. However, underestimations were observed on days when the "oasis-effect" occurred. Therefore, in future studies, special attention should be given to proper descriptions of the effects of advection on estimating ET for heterogeneous land surfaces. In addition, the canopy interception model should be coupled with the two-source ET model in long-term simulations.

\section{The Supplement related to this article is available online at doi:10.5194/gmd-7-1467-2014-supplement.}

Acknowledgements. We would like to thank J. Annan (Topical Editor) and the three anonymous reviewers for their critical reviews and helpful comments. We also thank Viola Hennecke (Typesetter) and Miguel Leyes (English Copy-Editor) for their continuous help during the review process and careful edits on the draft of the manuscript. The eddy covariance flux, meteorological, and other data used in this study are from Heihe Watershed Allied Telemetry Experimental Research (HiWATER) (http://heihedata.org/hiwater). We thank all the scientists, engineers and students who participated in HiWATER field campaigns. This research was supported by National Natural Science Foundation of China (no. 31370467), the Chinese Academy of Sciences Action Plan for West Development Program Project (KZCX2-XB3-15) and New Century Excellent Talents in University of the Chinese Ministry of Education (no. NCET-11-0219).

Edited by: J. Annan

\section{References}

Allen, R. G., Pereira, L. S., Raes, D., and Smith, M.: Crop evapotranspiration- guidelines for computing crop water requirements, FAO Irrigation and Drainage Paper, No. 56, FAO, Rome, 1998.

Anadranistakis, M., Liakatas, A., Kerkides, P., Rizos, S., Gavanosis, J., and Poulovassilis, A.: Crop water requirements model tested for crops grown in Greece, Agr. Water Manage., 45, 297-316, 2000.

Bastola, S., Murphy, C., and Sweeney, J.: The role of hydrological modelling uncertainties in climate change impact assessments of Irish river catchments, Adv. Water Resour., 34, 562-576, 2011.

Beven, K.: Changing ideas in hydrology-The case of physicallybased model, J. Hydrol., 105, 157-172, 1989. 
Beven, K.: How far can we go in distributed hydrological modelling?, Hydrol. Earth Syst. Sci., 5, 1-12, doi:10.5194/hess-5-12001, 2001.

Beven, K. J., Smith, P. J., and Freer, J. E.: So just why would a modeller choose to be incoherent?, J. Hydrol., 354, 15-32, 2008.

Bouten, W., Schaap, M. G., Aerts, J., and Vermetten, A. W. M.: Monitoring and modelling canopy water storage amounts in support of atmospheric depositions studies, J. Hydrol., 181, 305321, 1996.

Braswell, B., Sacks, W. J., Linder, E., and Schimel, D. S.: Estimating diurnal to annual ecosystem parameters by synthesis of a carbon flux model with eddy covariance net ecosystem exchange observations, Global Change Biol., 11, 1-21, 2005.

Brigode, P., Oudin, L., and Perrin, C.: Hydrological model parameter instability: A source of additional uncertainty in estimating the hydrological impacts of climate change?, J. Hydrol., 476, 410-425, 2013.

Clark, J. S. and Gelfand, A. E.: A future for models and data in environmental science, Trends Ecol. Evol., 12, 375-380, 2006.

Daamen, C., Simmonds, L. E., Wallace, J. S., Laryea, K. B., and Sivakumar, M. U. K.: Use microlysimeters to measure evaporation from sandy soils, Agr. Forest Meteor., 65, 159-173, 1993.

Engeland, K., Braud, I., Gottschalk, L., and Leblois, E.: Multiobjective regional modeling, J. Hydrol., 327, 339-35, 2006.

Evett, S. R., Kustas, W. P., Gowda, P. H., Anderson, M. A., Prueger, J. H., and Howell, T. A.: Overview of the Bushland Evapotranspiration and Agricultural Remote sensing EXperiment 2008 (BEAREX08): A field experiment evaluating methods for quantifying ET at multiple scales, Adv. Water Resour., 50, 4-19, 2012.

Falge, E., Baldocchi, D., Olson, R., Anthoni, P., Aubinet, M., Bernhofer, C., Burba, G., Ceulemans, R., Clement, R., Dolman, H., Granier, A., Gross, P., Grünwald, T., Hollinger, D., Jensen, N.O., Katul, G., Keronen, P., Kowalski, A., Lai, C. T., Lawc, B. E., Meyers, T., Moncrieff, J., Moors, E., Munger, J. W., Pilegaard, K., Rannik, Ü., Rebmann, C., Suyker, A., Tenhunen, J., Tu, K., Verma, S., Vesala, T., Wilson, K., and Wofsy, K.: Gap filling strategies for defensible annual sums of net ecosystem exchange, Agr. Forest Meteorol., 107, 43-69, 2001.

Fenicia, F., Savenije, H. H. G., Matgen, P., and Pfister, L.: A comparison of alternative multiobjective calibration strategies for hydrological modeling, Water Resour. Res., 43, W03434, doi:10.1029/2006WR005098, 2007.

Ferretti, D., Pendall, E., Morgan, J., Nelson, J., LeCain, D., and Mosier, A.: Partitioning evapotranspiration fluxes from a Colorado grassland using stable iostopes: seasonal variations and ecosystem implications of elevated atmospheric $\mathrm{CO}_{2}$, Plant Soil, 254, 291-303, 2003.

Flumignan, D. L., Faria, R. T., and Prete, C. E. C.: Evapotranspiration components and dual crop coefficients of coffee trees during crop production, Agr. Water Manage., 98, 791-800, 2011.

Franks, S. W. and Beven, K. J.: Bayesian estimation of uncertainty in land surface-atmosphere flux predictions, J. Geophys. Res.Atmos., 102, 23991-23999, 1997.

Franks, S. W., Beven, K. J., Quinn, P. F., and Wright, I. R.: On the sensitivity of soil-vegetation-atmosphere transfer (SVAT) schemes: equifinality and the problem of robust calibration, Agr. Forest Meteor., 86, 63-75, 1997.
Gash, J. H. C., Lloyd, C. R., and Lachaud, G.: Estimating sparse forest rainfall interception with an analytical model, J. Hydrol., 170, 79-86, 1995.

Gelman, A. and Rubin, D. B.: Inference from Iterative Simulation Using Multiple Sequences, Stat. Sci., 7, 457-511, 1992.

Gelman, A. B., Carlin, J. S., Stern, H. S., and Rubin, D. B.: Bayesian Data Analysis, Texts in Stat. Sci. Ser., edited by: Chatfield, C. and Zidek, J. V., CRC Press, Boca Raton, Florida, 1995.

Hanan, N. P. and Prince, S. D.: Stomatal conductance of westcentral supersite vegetation in HAPEX-Sahel: measurements and empirical model, J. Hydrol., 188-189, 536-562, 1997.

Harris, P. P., Huntingford, C., Cox, P. M., Gash, J. H. C., and Malhi, Y.: Effect of soil moisture on canopy conductance of Amazonian rainforest, Agr. Forest Meteor., 122, 215-227, 2004.

Hastings, W. K.: Monte Carlo sampling methods using Markov chains and their applications, Biometrika, 57, 97-109, 1970.

Hollinger, D. Y. and Richardson, A. D.: Uncertainty in eddy covariance measurements and its application to physiological models, Tree Physiol., 25, 873-885, 2005.

Hrachowitz, M., Savenije, H., Bogaard, T. A., Tetzlaff, D., and Soulsby, C.: What can flux tracking teach us about water age distribution patterns and their temporal dynamics?, Hydrol. Earth Syst. Sci., 17, 533-564, doi:10.5194/hess-17-533-2013, 2013a.

Hrachowitz, M., Savenije, H. H. G., Blöschl, G., McDonnell, J. J., Sivapalanf, M., Pomeroy, J. W., Arheimer, B., Blumei, T., Clark, M. P., Ehret, U., Feniciaal, F., Freer, J. E., Gelfann, A., Guptao, H. V., Hughes, D. A., Hut, R. W., Montanari, A., Pandea, S., Tetzlaff, D., Trocho, P. A., Uhlenbrook, S., Wagener, T., Winsemius, H. C., Woods, R. A., Zehek, E., and Cudennec, C.: A decade of Predictions in Ungauged Basins (PUB) - a review, Hydrolog. Sci. J., 58, 1198-1255, 2013b.

$\mathrm{Hu}, \mathrm{Y} . \mathrm{Q} .:$ Research advance about the energy budget and transportation of water vapour in the HEIFE area, Adv. Earth Sci., 9, 30-34, 1994 (in Chinese with English abstract).

Hu, Z. M., Yu, G. R., Zhou, Y. L., Sun, X. M., Li, Y. N., Shi, P. L., Wang, Y. F., Song, X., Zheng, Z. M., Zhang, L., and Li, S. G.: Partitioning of evapotranspiration and its controls in four grassland ecosystems: Application of a two-source model, Agr. Forest Meteor., 149, 1410-1420, 2009.

Hurtt, G. C. and Armstrong, R. A.: A pelagic ecosystem model calibrated with BATS data, Deep-Sea Res. Pt. II, 43, 653-683, 1996.

Iman, R. L. and Helton, J. C.: An investigation of uncertainty and sensitivity analysis techniques for computer models, Risk Anal., 8, 71-90, 1988.

Jarvis, P. G.: The interpretation of the variations in leaf water potential and stomatal conductance found in canopies in the field, Philos. T. Roy. Soc. B., 273, 563-610, 1976.

Kato, T., Kimura, R., and Kamichika, M.: Estimation of evapotranspiration, transpiration ratio and water-use efficiency from a sparse canopy using a compartment model, Agr. Water Manage., 65, 173-191, 2004.

Kavetski, D., Kuczera, G., and Franks, S. W.: Bayesian analysis of input uncertainty in hydrological modeling: 1 . Theory. Water Resour. Res., 42, W03407, doi:10.1029/2005WR004368, 2006.

Knorr, W. and Kattge, J.: Inversion of terrestrial ecosystem model parameter values against eddy covariance measurements by Monte Carlo sampling, Global Change Biol., 11, 1333-1351, 2005 . 
Korner, C., Schecl, J. A., and Bauer, H.: Maximum leaf diffusive conductance in vascular plants, Phorosynrherica, 13, 45-82, 1979.

Legates, D. R. and McCabe, G. J.: Evaluating the use of "goodnessof-fit" measures in hydrologic and hydroclimatic model validation, Water Resour. Res., 35, 233-241, 1999.

Lemon, E. R., Glaser, A. H., and Satterwhite, L. E.: Some aspects of the relationship of soil, plant, and meteorological factors to evapotranspiration, Proc. Soil Sci. Soc. Amer., 21, 464-468, 1957.

Lhomme, J. P., Montes, C., Jacob, F., and Prévot, L.: Evaporation from Heterogeneous and Sparse Canopies: On the Formulations Related to Multi-Source Representations, Bound.-Lay. Meteorol., 144, 243-262, 2012.

Li, S. E., Kang, S. Z., Zhang, L., Ortega-Farias, S., Li, F. S., Du, T. S., Tong, L., Wang, S. F., Ingman, M., and Guo, W. H.: Measuring and modeling maize evapotranspiration under plastic filmmulching condition, J. Hydrol., 503, 153-168, 2013 a.

Li, X., Cheng, G. D., Liu, S. M., Xiao, Q., Ma, M. G., Jin, R., Che, T., Liu, Q. H., Wang, W. Z., Qi, Y., Wen, J. G., Li, H. Y., Zhu, G. F., Guo, J. W., Ran, Y. H., Wang, S. G., Zhu, Z. L., Zhou, J., Hu, X. L., and Xu, Z. W.: Heihe Watershed Allied Telemetry Experimental Research (HiWATER): Scientific objectives and experimental design 1, B. Am. Meteorol. Soc., 94, 1145-1160, 2013 b.

Liu, C. M., Zhang, X. Y., and Zhang, Y. Q.: Determination of daily evaporation and evapotranspiration of winter wheat and maize by large-scale weighing lysimeter and micro-lysimeter, Agr. Forest Meteor., 111, 109-120, 2002.

Liu, S. M., Xu, Z. W., Wang, W. Z., Jia, Z. Z., Zhu, M. J., Bai, J., and Wang, J. M.: A comparison of eddy-covariance and large aperture scintillometer measurements with respect to the energy balance closure problem, Hydrol. Earth Syst. Sci., 15, 1291-1306, doi:10.5194/hess-15-1291-2011, 2011.

Liu, S. M., Li, X., Xu, Z. W., Xiao, Q., Ma, M. G., Jin, R., Wen, X. F., Shi, S. J., Guo, J. W., Wang, W. Z., He, X. B., Zhu, Z. L., Sun, R., Che, T., Xu, T. R., Jia, Z. Z., Zhao, Q. Y., and Wang, J. M.: The Multi-Scale Observation Experiment on Evapotranspiration over heterogeneous land surfaces (HiWATER-MUSOEXE): Flux Observation Matrix, J. Geophys. Res., in preparation, 2014.

Lund, M. R. and Soegaard, H.: Modelling of evaporation in a sparse millet crop using a two-source model including sensible heat advection within the canopy, J. Hydrol., 280, 124-144, 2003.

Mann, J. and Lenschow, D. H.: Errors in airborne flux measurements, J. Geophys. Res., 99, 14519-14526, 1994.

Metropolis, N. R., Rosenbluth, A. W., Rosenbluth, M. N., and Teller, A. H.: Equations of state calculations by fast computing machines, J. Chem. Phys., 21, 1087-1091, 1953.

Mo, X. G., Lin, Z. H., Xiang, Y. Q., and Liu, S. X.: Characteristics of incoming radiation through maize canopy, Eco-agriculture Research, 8, 1-4, 2000.

Morison, J. I. L., Baker, N. R., Mullineaux, P. M., and Davies, W. J.: Improving water use in crop production, Philos. T. Roy. Soc. B., 363, 639-658, 2008.

Moussa, R. and Chahinian, N.: Comparison of different multiobjective calibration criteria using a conceptual rainfall-runoff model of flood events, Hydrol. Earth Syst. Sci., 13, 519-535, doi:10.5194/hess-13-519-2009, 2009.

Mulder, J. P. M.: Simulating interception loss using standard meteorological data. The Forest-Atmosphere Interaction, edited by: Hutchison, B. and Hicks, B., D. Reidel, 177-196, 1985.
Noilhan, J. and Planton, S.: A simple parameterization of land surface processes for meteorological Models, Mon. Weather Rev., 117, 536-549, 1989.

Ogink-Hendriks, M. J.: Modelling surface conductance and transpiration of an oak forest in the Netherlands. Agr. Forest Meteorol., 74, 99-118, 1995.

Oke, T. R.: Boundary layer Climates, 2nd Edn., Mathuen, London, 1978.

Ortega-Farias, S., Carrasco, M., Olioso, A., Acevedo, C., and Poblete, C.: Latent heat flux over a Cabernet Sauvignon vineyard using the Shuttleworth and Wallace model, Irrig. Sci., 25, 161-170, 2007.

Ortega-Farias, S., Poblete-Echeverria, C., and Brisson, N.: Parameterization of a two-layer model for estimating vineyard evapotranspiration using meteorological measurements, Agr. Forest Meteor., 150, 276-286, 2010.

Parlange, M. B. and Katul, G. G.: An advection-aridity evaporation model, Water Resour. Res., 28, 127-132, 1992.

Poblete-Echeverria, C. and Ortega-Farias, S.: Estimation of actual evapotranspiration for a drip-irrigated Merlot vineyard using a three-source model, Irrig. Sci., 28, 65-78, 2009.

Pospisilova, J. and Solarova, J.: Environmental and biological control of diffusive conductance of adaxial and abaxial leaf epidermis, Photosyntherica, 14, 90-127, 1980.

Rana, G. and Katerji, N.: Measurement and estimation of actual evapotranspiration in the field under Mediterranean climate: a review, Eur. J. Agron., 13, 125-153, 2000.

Rao, K., Wyngaard, J., and Cote, O.: Local advection of momentum, heat, and moisture in micrometeorology, Bound.-Lay. Meteorol., 7, 331-348, 1974

Raupach, M. R., Rayner, P. J., Barrett, D. J., Defries, R. S., Heimann, M., Ojima, D. S., Quegan, S., and Schmullius, C. C.: Model-data synthesis in terrestrial carbon observation: methods, data requirements and data uncertainty specifications, Global Change Biol., 11, 378-397, 2005.

Richardson, A. D., Hollinger, D. Y., Burba, G. G., Davis, K. J., Flanagan, L. B., Katul, G. G., Williammunger, J., Ricciuto, D. M., Stoy, P. C., Suyker, A. E., Verma, S. B., and Wofsy, S. C.: A multi-site analysis of random error in tower-based measurements of carbon and energy fluxes, Agr. Forest Meteorol., 136, 1-18, 2006.

Richardson, A. D., Mahecha, M. D., Falge, E., Kattge, J., Moffat, A. M., Papale, D., Reichstein, M., Stauch, V. J., Braswell, B. H., Churkina, G., Kruijt, B., and Hollinger, D. Y.: Statistical properties of random $\mathrm{CO}_{2}$ flux measurement uncertainty inferred from model residuals, Agr. Forest Meteor., 148, 38-50, 2008.

Richardson, A. D., Williams, M., Hollinger, D. Y., Moore, D. J. P., Dail, D. B., Davidson, E. A., Scott, N. A., Evans, R. S., Hughes, H., Lee, J. H., Rodrigues, C., and Savage, K.: Estimating parameters of a forest ecosystem $\mathrm{C}$ model with measurements of stocks and fluxes as joint constraints, Oecologia, 164, 25-40, 2010.

Rutter, A. J., Kershaw, K. A., Robbins, P. C., and Morton, A. J.: A predictive model of rainfall interception in forests. I. Derivation of the model from observations in a plantation of Corsican pine, Agr. Forest Meteor., 9, 367-384, 1971.

Samanta, S., Mackay, D. S., Clayton, M. K., Kruger, E. L., and Ewers, B. E.: Bayesian analysis for uncertainty estimation of a canopy transpiration model, Water Resour. Res., 43, W04424, doi:10.1029/2006WR005028, 2007. 
Sauer, T. J., Singer J. W., Prueger, J. H., DeSutter, T. M., and Hatfield, J. L.: Radiation balance and evaporation partitioning in a narrow-row soybean canopy, Agr. Forest Meteor., 145, 206-214, 2007.

Scott, R. L., Huxman, T. E., Cable, W. L., and Emmerich, W. E.: Partitioning of evapotranspiration and its relation to carbon dioxide exchange in a Chihuahuan desert shrubland, Hydrol. Process., 20, 3227-3243, 2006.

Sellers, P. J., Heiser, M. D., and Hall, F. G.: Relations between surface conductance and spectral vegetation indices at intermediate $\left(100 \mathrm{~m}^{2}\right.$ to $\left.15 \mathrm{~km}^{2}\right)$ length scales, J. Geophys. Res., 97, 1903319059, 1992.

Shuttleworth, W. J. and Gurney, R. J.: The theoretical relationship between foliage temperature and canopy resistance in sparse crops, Q. J. Roy. Meteorol. Soc., 116, 497-519, 1990.

Shuttleworth, W. J. and Wallace, J. S.: Evaporation from sparse crops- an energy combination theory, Q. J. Roy. Meteorol. Soc., 111, 839-855, 1985.

Stannard, D. I.: Comparison of Penman-Monteith, ShuttleworthWallace and modified Priestley-Taylor evapotranspiration models for wildland vegetation in semiarid rangeland, Water Resour. Res., 29, 1379-1392, 1993.

Stewart, J. B.: Modelling surface conductance of pine forest, Agr. Forest Meteor., 43, 19-35, 1988.

Sun, H. Y., Shao, L. W., Liu, X. W., Miao, W. F., Chen, S. Y., and Zhang, X. Y.: Determination of water consumption and the water-saving potential of three mulching methods in a jujube orchard, Eur. J. Agron., 43, 87-95, 2012.

Sun, S. F.: Moisture and heat transport in a soil layer forced by atmospheric conditions, M.S. thesis, University of Connecticut, 1982.

Teh, C. B. S., Simmonds, L. P., and Wheeler, T. R.: Modelling the partitioning of solar radiation capture and evapotranspiration intercropping systems, in: Proceedings of the 2nd International Conference on Tropical Climatology, Meteorology and Hydrology TCMH-2001, Brussels, Belgium, 2001.

Tourula, T. and Heikinheimo, M.: Modelling evapotranspiration from a barley field over the growing season, Agr. Forest Meteor., 91, 237-250, 1998.

United Nations Environment Programme (UNEP): World Atlas of Desertification, London, Edward Arnold, 1992.

van de Griend, A. A. and Owe, M.: Bare soil surface resistance to evaporation by vapor diffusion under semiarid conditions, Water Resour. Res., 30, 181-188, 1994.

van Oijen, M., Rougier, J., and Smith, R.: Bayesian calibration of process-based forest models: bridging the gap between models and data, Tree Physiol., 25, 915-927, 2005.

van Oijen, M., Cameron, D. R., Butterbach-Bahl, K., Farahbakhshazad, N., Jansson, P. E., Kiese, R., Rahn, K. H., Werner, C., and Yeluripati, J. B.: A Bayesian framework for model calibration, comparison and analysis: application to four models for the biogeochemistry of a Norway spruce forest, Agr. Forest Meteor., 151, 1609-1621, 2011.

van Oijen, M., Reyer, C., Bohn, F. J., Cameron, D. R., Deckmyn, G., Flechsig, M., Härkönen, S., Hartig, F., Huth, A., Kiviste, A., Lasch, P., Mäkelä, A., Mette, T., Minunno, F., and Rammer, W.: Bayesian calibration, comparison and averaging of six forest models, using data from Scots pine stands across Europe, Forest Ecol. Manage., 289, 255-268, 2013.
Verhoef, A. and Allen, S. J.: A SVAT scheme describing energy and $\mathrm{CO}_{2}$ fluxes for multi-component vegetation: calibration and test for a Sahelian savannah, Ecol. Model., 127, 245-267, 2000.

Verhoef, A., Fernández-Gálvez, J., Diaz-Espejo, A., Main, B. E., and El-Bishti, M.: The diurnal course of soil moisture as measured by various dielectric sensors: effects of soil temperature and the implications for evaporation estimates, J. Hydrol., 321, 147-162, 2006.

Verhoef, A., Ottle, C., Cappelaere, B., Murray, T., Saux-Picart, S., Zribi, M., Maignan, F., Boulain, N., Demarty, J., and Ramier, D.: Spatio-temporal surface soil heat flux estimates from satellite data: results for the AMMA experiment at the Fakara (Niger) supersite, Agr. Forest Meteor., 154-155, 55-66, 2012.

Villagarcía, L., Were, A., García, M., and Domingo, F.: Sensitivity of a clumped model of evapotranspiration to surface resistance parameterisations: Application in a semi-arid environment, Agr. Forest Meteor., 150, 1065-1078, 2010.

Wallace, J. S. and Verhoef, A.: Interactions in mixed-plant communities: light, water and carbon dioxide, in: Leaf development and canopy growth, edited by: Marshall, B. and Roberts, J. A., Sheffield biological science series, Sheffield Academic Press, Sheffield, 204-250, 2000.

Wang, J. M. and Mitsuta, Y.: Evaporation from the desert: some preliminary results of HEIFI, Bound.-Lay. Meteorol., 59, 413$418,1992$.

Wang, J. M., Zhuang, J. X., Wang, W. Z., Liu, S. M., and Xu, Z. W.: Assessment of Uncertainties in Eddy Covariance Flux Measurement Based on Intensive Flux Matrix of HiWATER-MUSOEXE, IEEE Geosci. Remote Sens., accepted, 2014.

Wang, X. F. and Yakir, D.: Using stable isotopes of water in evapotranspiration studies, Hydrol. Process., 14, 1407-1421, 2000.

Wang, Y. P., Leuning, R., Cleugh, H. A., and Coppin, P. A.: Parameter estimation in surface exchange models using nonlinear inversion: how many parameters can we estimate and which measurements are most useful?, Glob. Change Biol., 7, 495-510, 2001.

Williams, D. G., Cable, W., Hultine, K., Hoedjes, J. C. B., Yepez, E. A., Simonneaux, V., Er-Raki, S., Boulet, G., de Bruin, H. A. R., Chehbouni, A., Hartogensis, O. K., and Timouk, F.: Evapotranspiration components determined by stable isotope, sap flow and eddy covariance techniques, Agr. Forest Meteor., 125, 241-258, 2004.

Winsemius, H. C., Savenije, H. H. G., Gerrits, A. M. J., Zapreeva, E. A., and Klees, R.: Comparison of two model approaches in the Zambezi river basin with regard to model reliability and identifiability, Hydrol. Earth Syst. Sci., 10, 339-352, doi:10.5194/hess10-339-2006, 2006.

$\mathrm{Xu}, \mathrm{T}$., White, L., Hui, D., and Luo, Y.: Probabilistic inversion of a terrestrial ecosystem model: Analysis of uncertainty in parameter estimation and model prediction, Global Biogeochem. Cy., 20, GB2007, doi:10.1029/2005GB002468, 2006.

Xu, Z. W., Liu, S. M., Li, X., Shi, S. J., Wang, J. M., Zhu, Z. L., Xu, T. R., Wang, W. Z., and Ma, M. G.: Intercomparison of surface energy flux measurement systems used during the HiWATERUSOEXE, J. Geophys. Res., 118, 13140-13157, 2014.

Zhang, B. Z., Kang, S. Z., Li, F. S., and Zhang, L.: Comparison of three evapotranspiration models to Bowen ratio-energy balance method for a vineyard in an arid desert region of northwest China, Agr. Forest Meteor., 148, 1629-1640, 2008. 
Zhang, Q. and Huang, R. H.: Water vapor exchange between soil and atmosphere over a Gobi surface near an oasis in Summer, J. Appl. Meteorol., 43, 1917-1928, 2004.

Zhang, X.: Improvement of a Soil-Atmosphere-Transfer Model for the Simulation of Bare Soil Surface Energy Balances in Semiarid Areas, Asia-Pacific J. Atmos. Sci., 48, 97-105, 2012.

Zhao, W.-Z., Ji, X.-B., Kang, E.-S., Zhang, Z.-H., and Jin, B.-W.: Evaluation of Penman-Monteith model applied to a maize field in the arid area of northwest China, Hydrol. Earth Syst. Sci., 14, 1353-1364, doi:10.5194/hess-14-1353-2010, 2010.

Zhu, G. F., Li, Z. Z., Su, Y. H., Ma, J. Z., and Zhang, Y. Y.: Hydrogeochemical and isotope evidence of groundwater evolution and recharge in Minqin Basin, Northwest China, J. Hydrol., 333, 239-251, 2007.
Zhu, G. F., Su, Y. H., and Feng, Q.: The Hydrochemical Characteristics and Evolution of Groundwater and Surface Water in the Heihe River Basin, Northwest China, Hydrogeol. J., 16, 167182, 2008.

Zhu, G. F., Su, Y. H., Li, X., Zhang, K., and Li, C. B.: Estimating actual evapotranspiration from an alpine grassland on QinghaiTibetan plateau using a two-source model and parameter uncertainty analysis by Bayesian approach, J. Hydrol., 476, 42-51, 2013. 